U.S. DEPARTMENT OF COMMERCE

National Bureau of Standards

Center for Manufacturing Engineering

Mechanical Production Metrology Division

Washington, DC 20234

August 1982

Report to

Consumer Product Safety Commission

$-Q($

Bethesda, MD 20016 



\section{EVALUATION OF CHAIN SAW KICKBACK MOTION USING AN OPTOELECTRONIC MEASUREMENT SYSTEM}

Donald Robinson and Charles Federman

U.S. DEPARTMENT OF COMMERCE

National Bureau of Standards

Center for Manufacturing Engineering

Mechanical Production Metrology Division

Washington, DC 20234

August 1982

\section{Report to}

Consumer Product Safety Commission

Bethesda, MD 20016

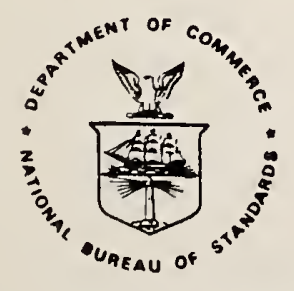

U.S. DEPARTMENT OF COMMERCE, Malcolm Baldrige, Secretary NATIONAL BUREAU OF STANDARDS, Ernest Ambler, Director 



\section{Table of Contents}

1. Introduction

2. Kickback Test Arrangement

3. Optoelectronic Measuring System

4. Experimental Program

4.1. Selection of Test Saws

4.2. Kickback Test Conditions

4.3. Volunteer Test Operators

5. Determination of Test Saw Rotational Displacements

6. Principal Test Results

6.1. Kickback Energy during Hand-Held Tests

6.2. Comparison of Saw Motion with Energy Measured in Kickback Machine

6.3. Evaluation of Low Kickback Energy Chain

6.4. Evaluation of Handle Spacing Effect on Saw Motion

7. Discussion

8. Acknowledgments

9. References

Appendix A. Development of Test Protocol

Appendix B. Human Factors, Recommendations, and Rationale for Testing Chain Saw Kickback with Volunteer Operators

Appendix C. Computer Analysis of Recorded Data 



\section{Introduction}

Background

In 1978, the Consumer Product Safety Commission (CPSC) accepted a proposal from the Chain Saw Manufacturers' Association (CSMA) to develop a voluntary performance standard to address the kickback hazard for chain saws. The process included participation by CPSC, the National Bureau of Standards (NBS), consumers, and industry in the development of kickback testing equipment and procedures, study of operator/saw interactions, and analysis of injury data. A kickback test machine (KBM) was adapted so that test procedures could be developed for assessing the kickback energy potential of chain saws. A report describing the exploratory chain saw kickback research at NBS in the joint effort with CPSC and the chain saw industry is given in Reference [1].

In 1980 the CPSC decided to initiate the in-house development of a mandatory standard to address chain saw kickback. Part of that effort involved relating known chain saw energy levels generated during kickback in the KBM to the final angle that a saw might travel when held in the hands of a chain saw operator. The present report describes the experimental program developed at NBS to determine the relationship between kickback energy and chain saw motion during hand-held kickbacks for selected samples of consumer-type chain saws and volunteer test subjects. The measurement system employed in this research included a computer-controlled optoelectronic system for measuring the displacements of selected points on the test saws, test fixture, and the right arm motion of selected test subjects during simulated kickbacks. Included in the report is a description of the test equipment and procedures, the experimental design, and analyses of the measured displacement data for chain saws having known values of kickback energy. 


\section{Kickback Test Arrangement}

In order to establish the relationship of energy during a simulated kickback to the kickback angle of a saw in the hands of a chain saw user, it was necessary to develop a suitable test fixture and outline the procedures before making the appropriate measurements. A KBM had been developed and shown in prior investigations by both NBS and the chain saw industry to simulate kickback conditions in a reproducible manner for determining the energy associated with chain saw kickback motion.1 Thus, the procedures successfully implemented for the KBM formed the basis for developing a test fixture for handheld tests of simulated kickbacks in the present investigation.

Kickback is initiated in the KBM by accelerating a carriage, holding a "wood" (i.e., medium density fiberboard) specimen, into contact with the moving saw chain on the upper quadrant of the saw guidebar nose. The method selected to accelerate the carriage, control its approach speed, and adjust the specimen contact angle for the hand-held tests was the same as that used in the KBM [1]. Figure 1 shows the fixture and test arrangement for the kickback experimental program.

In the hand-held kickback investigations, volunteer test subjects were required to hold an operating test saw in a simulated bucking mode of operation. (This procedure will be discussed in a later section.) During preliminary kickback tests, it was found necessary to constrain the rearward carriage motion as the kickback was initiated in order to adequately transfer the carriage momentum to the test saw via the wood-saw interaction. The test carriage momentum in the $\mathrm{KBM}$ is efficiently transferred to the test saw since the

\footnotetext{
${ }^{1}$ The Round Robin I kickback tests which demonstrated the interlaboratory
} reproducibility are discussed [1]. 


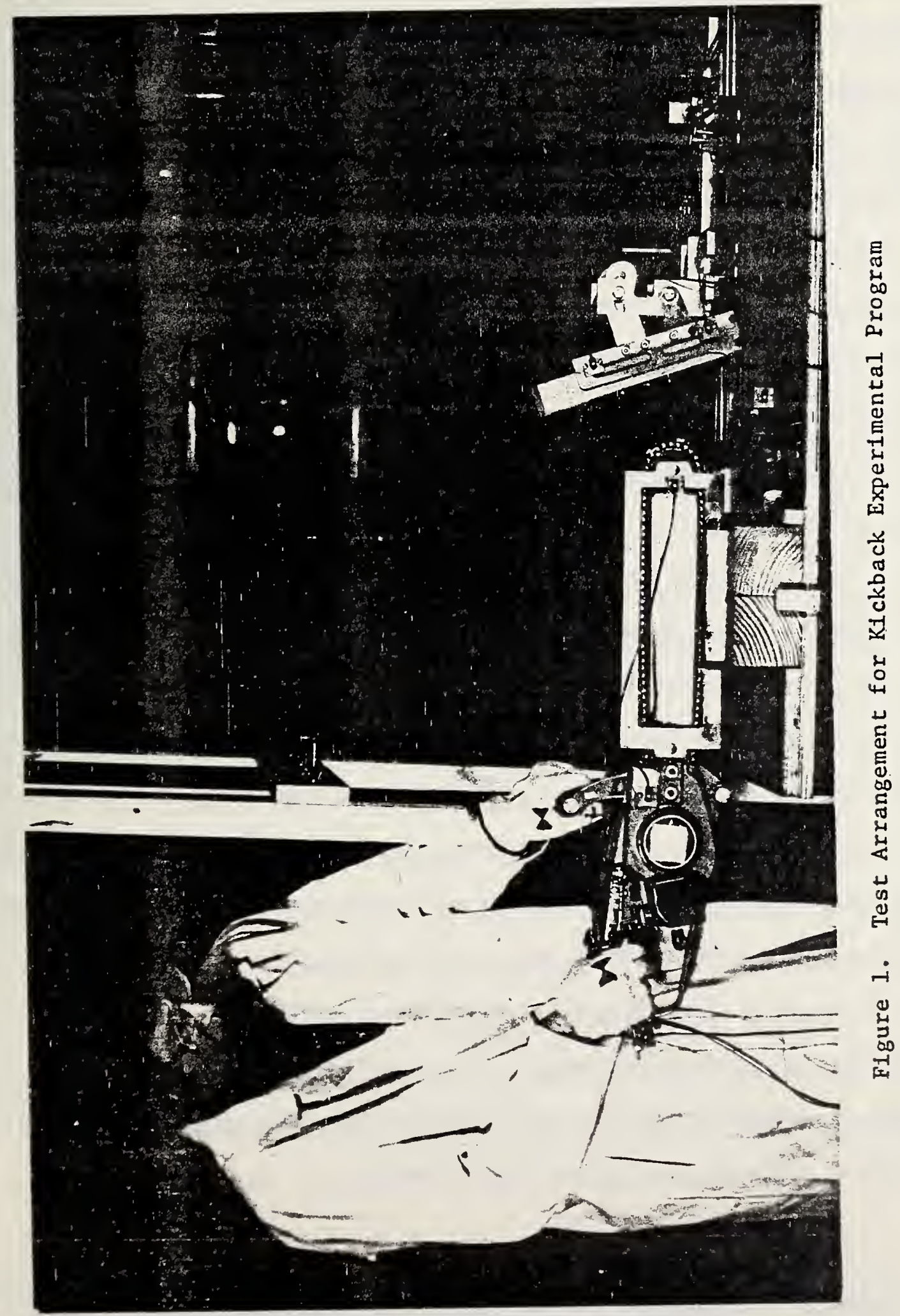


saw can only rotate about its center of gravity during kickback; i.e., the saw is constrained so that no lateral motion is permitted. Similar constraint of a test saw's initial motion during the hand-held kickback simulation of a bucking operation was considered, but was judged to be overly restrictive. The use of a pawl and rack mechanism in the test fixture to constrain the carriage's initial rearward motion was found to effectively transfer the carriage momentum to the saw without unrealistically constraining the test saw.

The initial horizontal position of a test saw in the KBM was controlled in a manner which prevented downward motion of the guidebar during a kickback test. For the hand-held test arrangement, the chain saw motion was similarly controlled by using a lightweight shield surrounding the flat portion of the guidebar as shown in figure 1. (Another purpose of the shield was to protect the test subjects ${ }^{1}$ ). This procedure served both to simulate a bucking mode of operation, wherein a $\log$ is cut by the chain on the straight portion of the guidebar, and to control the initial horizontal position of the guidebar to insure that the wood-saw contact angle was properly maintained.

The horizontal alignment of the guidebar shield, which rested on a wooden block, was monitored by the principal investigator during each kickback test. Immediately prior to the release of the test carriage to initiate a kickback, a technician would signal the test subject to adjust the saw alignment if necessary to insure that the guidebar was properly aligned in a vertical plane. The initial guidebar alignment in the vertical and horizontal planes was necessary in order to reproduce the same initial conditions as achieved during kickback tests in the Kickback Test Machine.

\footnotetext{
${ }^{1}$ A full discussion of the various safety precautions, which included a barrier to prevent excessive rotational saw motion is given in Appendix A.
} 


\section{Optoelectronic Measuring System}

An optoelectronic tracking system was used to measure $\mathrm{x}$ and $\mathrm{y}$ coordinates in real time at preselected locations on a test saw, the test fixture, and on several of the volunteer operators during the kickback experimental program. 2 Small light-emitting diodes (LED's) were attached to each test saw near the guidebar nose, the center of gravity, the rear handle, and at three other positions of interest on the test fixture or on the right arm of an operator. Figure 1 shows the typical test arrangement; for several tests, the diodes on the wood carriage were placed on the wrist and elbow of the operator.

The main component of the computer-controlled optoelectronic system is a specially-developed infrared camera having an analogue photodetector with four electrodes. When the infrared light from an LED is focused on the detector surface through the camera lens system, the generated photocurrent is divided among the four electrodes. The current is used to obtain two signals which are linearly related to the $\mathrm{x}$ and $\mathrm{y}$ coordinates of the LED. The resolution of the system digital output is specified as 1 part in 1024 (i.e., 10 bits).

For the kickback experimental program, the detector was used to measure the position of six LED's. 3 This was achieved by turning the LED's on and of $f$ at a rate of $312 \mathrm{~Hz}$. Thus, the time was $0.0032 \mathrm{sec}$. interval between successive tracking cycles measured during a kickback. The image field was scanned so that the $\mathrm{x}$ and $\mathrm{y}$ coordinates for each LED point location could be digitized and stored in a mini-computer memory for data reduction and analysis. The displacement data were visually observed on a video terminal following the first kickback test for each saw in order to check that the recording

2 The Selspot optoelectronic system was used in this investigation. Note: Commercial instruments and products are identified in this report in order to specify adequately the experimental procedure. In no case does such identification imply recommendation or endorsement by the National Bureau of Standards, nor does it imply that the equipment identified is necessarily the best available for the purpose.

${ }^{3} \mathrm{~A}$ maximum of 30 LED's can be tracked in one cycle. 
system was properly triggered. Coordinate-time data were stored on floppy disks, and a hard copy was subsequently printed to enable the kickback motion to be analyzed as described in other sections of this report.

\section{Experimental Program}

4.1. Selection of Test Saws

The CPSC provided 34 consumer-type chain saws from which to select saws for the experimental program. From this population of currently-manufactured saws, 5 gasoline and 2 electric chain saws were selected. Preliminary selection of the test saws was based only on the total kickback energy determined by CPSC with the Kickback Test Machine. Since some of the saws in this group were found to have relatively little kickback motion when held by each of several operators, a second group of saws was chosen taking into account the polar moment of inertia of the saw in addition to its kickback energy characteristics. The final selection took into account additional design features which provided somewhat greater diversity among the test saws. The general characteristics of the saws selected for the kickback experimental program are listed in table 1.

\subsection{Kickback Test Conditions}

During the preliminary hand-held kickback tests to select the test saws for the experimental program, the saws were tested at conditions where the total energy obtained in the KBM was found to be maximum. After the test saws were selected, it was found that somewhat larger kickback motion would result if the saws, when held by an operator, were tested at conditions where the rotational energy obtained in the KBM was at a maximum.

A list of the kickback test parameters which were used for the chain saws in the experimental program is given in table 2. The maximum values for rotational energy as determined in the KBM are also noted in this table. 
Table 1. Characteristics of chain saws in hand-held kickback experimental program

\begin{tabular}{lcccccc}
$\begin{array}{c}\text { Chain } \\
\text { Saw }\end{array}$ & $\begin{array}{c}\text { Weight } \\
\mathrm{N}(\mathrm{lbf})\end{array}$ & $\begin{array}{c}\text { Guidebar } \\
\text { Length } \\
\mathrm{cm}(\mathrm{in})\end{array}$ & Chain Type & $\begin{array}{c}\text { Polar Inertia } \\
\mathrm{m}-\mathrm{N}-\mathrm{sec}^{2} \\
\left.\text { in-1bf-sec }^{2}\right)\end{array}$ & $\begin{array}{c}\text { Total } \\
\text { Energy } \\
\text { joule } \\
\text { (in-1bf) }\end{array}$ \\
\hline G1 (1.6) & $2.270(10.10)$ & $30.48(12)$ & Low Profile & $0.0617(0.546)$ & $12.6(112)$ \\
G2 (2.0) & $2.172(9.66)$ & $30.48(12)$ & Low Profile & $0.0651(0.576)$ & $13.6(120)$ \\
G3(2.1) & $2.934(13.05)$ & $35.56(14)$ & Low Profile & $0.0942(0.834)$ & $10.7 \quad(95)$ \\
G4(2.6) & $2.967(13.20)$ & $40.64(16)$ & Standard & $0.1321(1.169)$ & $36.3(321)$ \\
G5(3.6) & $3.992(17.76)$ & $40.64(16)$ & Standard & $0.1527(1.351)$ & $51.8(458)$ \\
E6 (2.25) & $2.423(10.78)$ & $35.56(14)$ & Low Energy & $0.0584(0.517)$ & $9.6(85)$ \\
E7 (2.0) & $2.774(12.34)$ & $35.56(14)$ & Top Sharp & $0.0817(0.723)$ & $11.9(105)$
\end{tabular}

${ }^{1}$ For gasoline-powered saws, designated by "G," the number in parentheses represents the engine cubic-inch displacement. For electric-powered saws, designated by "E," the number in parentheses represents the engine horsepower capacity.

${ }^{2}$ All the guidebars were equipped with a sprocket nose, and each of the latter were symmetric except for Saw E7.

${ }^{3}$ The kickback energy was measured in the Kickback Test Machine at those conditions producing the maximum value of rotational energy. The same test conditions were used in the hand-held kickback program and are given in table 2. 
Table 2. Test parameters for the hand-held kickback experimental program 1

\begin{tabular}{|c|c|c|c|c|c|}
\hline Test Saw & $\begin{array}{r}\text { Rotat } \\
\text { jou }\end{array}$ & $\begin{array}{l}1 \text { Energy } \\
\text { in-1bf) }\end{array}$ & $\begin{array}{c}\text { Contact Angle } \\
\text { (deg) }\end{array}$ & $\begin{array}{c}\text { Engine Speed } \\
\text { (rpm) }\end{array}$ & $\begin{array}{c}\text { Approach Speed } \\
(\mathrm{in} / \mathrm{sec})\end{array}$ \\
\hline G1 & 9.5 & (84) & 20 & 10,000 & 30 \\
\hline G2 & 11.1 & $(98)$ & 15 & 11,000 & 35 \\
\hline G3 & 9.7 & $(86)$ & 15 & 11,000 & 35 \\
\hline G4 & 32.5 & (288) & 15 & 9,500 & 25 \\
\hline G5 & 46.7 & $(413)$ & 10 & 11,500 & 30 \\
\hline E6 & 8.6 & $(76)$ & 20 & 7,200 & 20 \\
\hline E7 & 8.7 & $(67)$ & 10 & 7,200 & 35 \\
\hline
\end{tabular}

\footnotetext{
${ }^{1}$ The warm-up, clutch-burn or torque, and chain-tension procedures for the hand-held saws were the same as the test procedures developed for use with the Kickback Test Machine. The test saws and chains were broken in by the CPSC prior to conducting the hand-held experimental program.

${ }^{2}$ Determined by CPSC using the Kickback Test Machine.
} 


\subsection{Volunteer Test Operators}

A total of 9 male and 2 female volunteers served as test operators in the hand-held kickback program. Selection of the volunteer subjects and other human factors aspects of the experimental design for the program were developed under the guidance of a research psychologist. Detailed information concerning the latter topics, including the test subject profiles, are given in Appendix B.

Prior to testing, the principal investigator orally gave each subject the following instructions, which had been prepared by a research psychologist:

"It is very important that you understand the following instructions:

What we want you to do is to pretend that you are cutting a log. Let the chain saw rest on the wooden block and pretend it is cutting its way through it. Do not lean into or push down on the saw. When you get the saw in the correct position, just hold it steady. Do you have any questions?"

Prior to the tests for each saw, the principal investigator demonstrated a kickback for that particular saw. The safety bar height was then adjusted so that the subject could not see when the wood carriage was released to initiate the kickback motion. The subject was given an opportunity to experience several kickbacks as part of the indoctrination before the kickback motion was measured for five consecutive tests for each saw.

\section{Determination of Test Saw Rotational Displacements}

For most of the kickback tests, the LED's, whose coordinates were measured in real time during a kickback, were placed on both the test saw and the test fixture. Three diodes were always located on the test saw: a) on the guidebar shield near the nose tip of the guidebar, b) near the saw center of gravity, and c) near the rear handle of the saw. Usually, three diodes were also located on the test fixture, one at a fixed reference position at the base of the carriage rails and two on the clamp of the moving carriage. 
The primary purpose of the reference diode at the base of the carriage rails was to ensure that the camera set up of the measuring system was the same for the various tests, since the instrumentation was frequently disassembled after a test and reassembled for succeeding tests. 4 The purpose of the diodes mounted on the carriage clamp was to check the angle of the wood specimen and to monitor the carriage motion during the kickback. Since the contact angle and carriage speed were accurately measured with other equipment, the coordinate data at these positions were additional indicators that these parameters were correctly adjusted. For several of the kickback tests, the diodes were removed from the carriage clamp and placed on the wrist and elbow of the test subject. The coordinate data for these positions were then used to plot the motion of the right-arm wrist and elbow for several of the larger male test subjects. This information was used in an evaluation of the motion produced in the Human Factors Apparatus (HFA), the data for which will be presented in a separate report [2].

The coordinate-time data for the diodes mounted on the test saws were analyzed in this investigation. Primary emphasis was placed on evaluation of the saw rotation, because of the severity of kickback injuries associated with such displacements [3].

Criteria and Method for Assessing the Kickback Angle. The method for assessing the kickback angle for this preliminary analysis was chosen on the basis of the CPSC evaluation of the apparent angle of rotation from in-depth investigation reports (IDIR's) of chain-saw accidents. This angle is measured as though a saw rotates about a point in line with the top of the guidebar at point a on that line (Iine A) where it is intersected by another line (line B) perpendicular to it and

\footnotetext{
${ }^{4}$ The instrumentation was required for another research activity which ran concurrently with the kickback experimental program.
} 
touching the rearmost part of the rear handle (see figure 2). Another line is then drawn from this point to the point of chain contact with the operator (line C), as shown. The angle from line A lying along the top of the guidebar to line $\mathrm{C}$ about point a was measured in the IDIR's as the apparent angle of rotation. This approach was developed by the CPSC as a measure of the difference between the position of the saw just prior to kickback and the location of the body part injured.

This criterion for assessing the apparent kickback angle implies that the operator's right hand continues to grip the saw's rear handle for the duration of the kickback. There was no method for evaluating this assumption prior to conducting the experimental program. Other postulated methods for assessing the kickback angle depended similarly on assumptions which could not be evaluated prior to conducting the experimental program.

In the analysis of the saw LED (diode) coordinate data to compute the derived angle of rotation (DAR), a correction was made so that the rear handle diode position was adjusted to lie along line $B$ in figure 2. A second correction was made to account for the fact that the diode at the end of the guidebar was, in general, not aligned with the rear handle diode. Although other modifications to the recorded data were omitted for this preliminary analysis, an estimate was made of their influence on the kickback angles. These second-order corrections will be discussed in a later section of this report. It should be noted that the operator's control of the saw for the CPSC kickback angle criterion, based upon IDIR's, was confirmed during the experimental program: the test subjects naintained right-hand grip of the rear handle throughout the kickback for all the tests.

The derived angle of rotation (DAR) was determined from the digitized coordinate data as follows: 


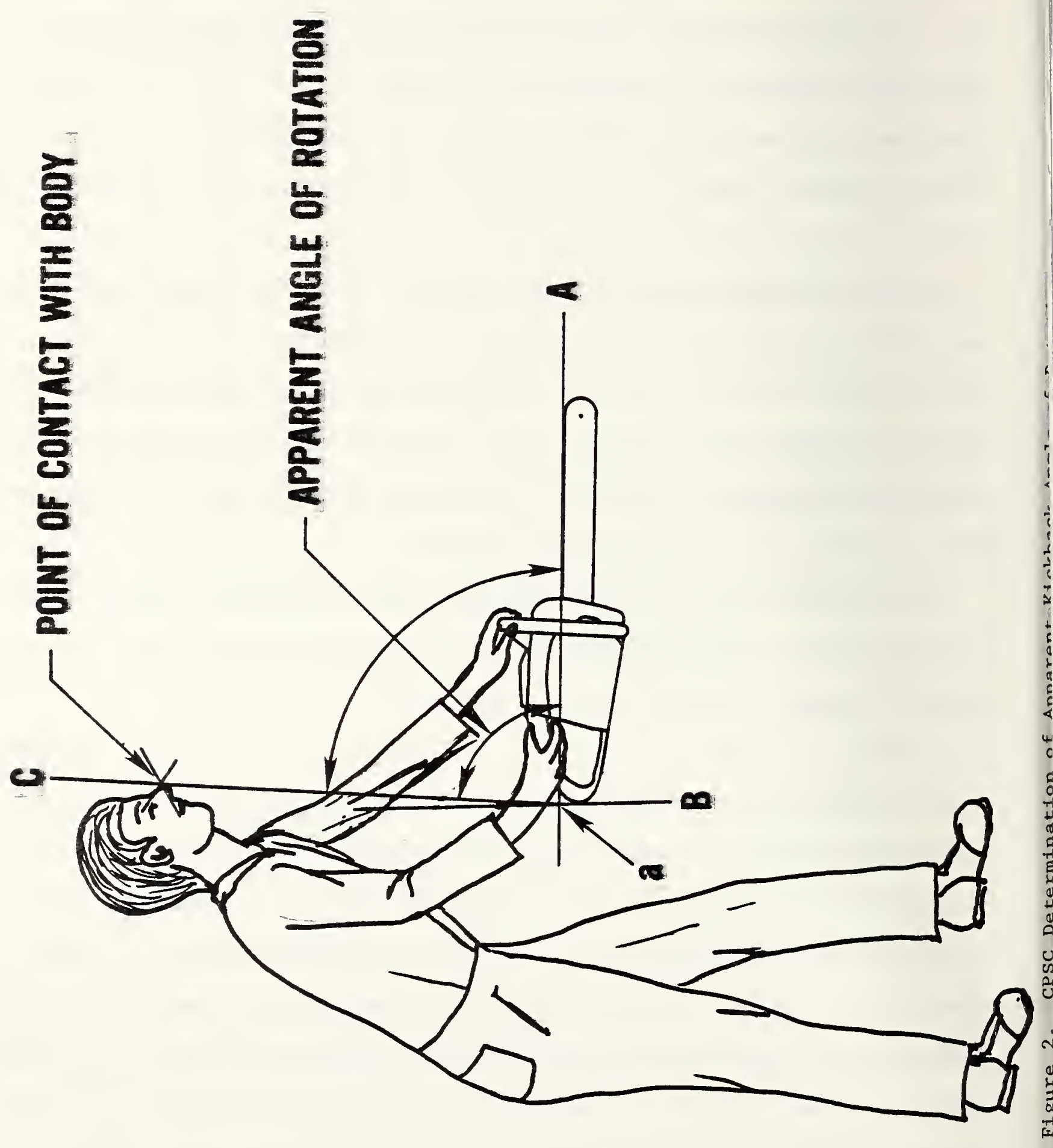




$$
\mathrm{DAR}=\mathrm{DAR}_{1}+\mathrm{DAR}_{2} \text {, }
$$

where $\mathrm{DAR}_{1}$ is the angle through which the guidebar rotates above a horizontal line passing through the rearmost part of the rear handle, i.e., $\left(\mathrm{X}_{50}, \mathrm{Y}_{50}\right)$ as shown in figure 3. Since the diode located at the end of the guidebar, having coordinates $\left(\mathrm{X}_{3}, \mathrm{Y}_{3}\right)$, was generally not located on this horizontal line when the saw was held as the kickback was initiated, the term $\mathrm{DAR}_{2}$ was added to $\mathrm{DAR}_{1}$ to incorporate the angular travel of this diode before it reached the horizontal. The complete equation is:

$$
\mathrm{DAR}=\tan ^{-1}\left[\left(\mathrm{Y}_{3}-\mathrm{Y}_{50}\right) /\left(\mathrm{X}_{50}-\mathrm{X}_{3}\right)\right]+\tan ^{-1}\left[\left(\mathrm{Y}_{50}-\mathrm{Y}_{30}\right) /\left(\mathrm{X}_{50}-\mathrm{X}_{30}\right)\right]
$$

where $\left(\mathrm{X}_{30}, \mathrm{Y}_{30}\right)$ are the diode coordinates at the end of the guidebar at initiation of kickback (time $t=0$ ); the sign conventions for the displacenent measuring system are shown in figure 3.

Before the derived angle of rotation could be computed, it was first necessary to determine when the test saw was contacted by the wood specimen. The best indication was vertical motion recorded from the diode placed near the tip of the saw guidebar. Contact with the wood occurred just prior to the first indication of guidebar vertical motion. Thus, the displacements measured for the diode positions one measurement sample $(0.003 \mathrm{sec})$ prior to the latter motion were taken to define the initial diode coordinates as contact was made. The coordinate data were printed out in units of the optoelectronic measurement system, which were subsequently used to estinate the derived angles of rotation for an initial analysis.

Since the diode located near the rear handle of each test saw was not precisely in the desired reference position, a correction was made to the initial coordinates for this diode to compute the kickback angles as shown in figure 3. 


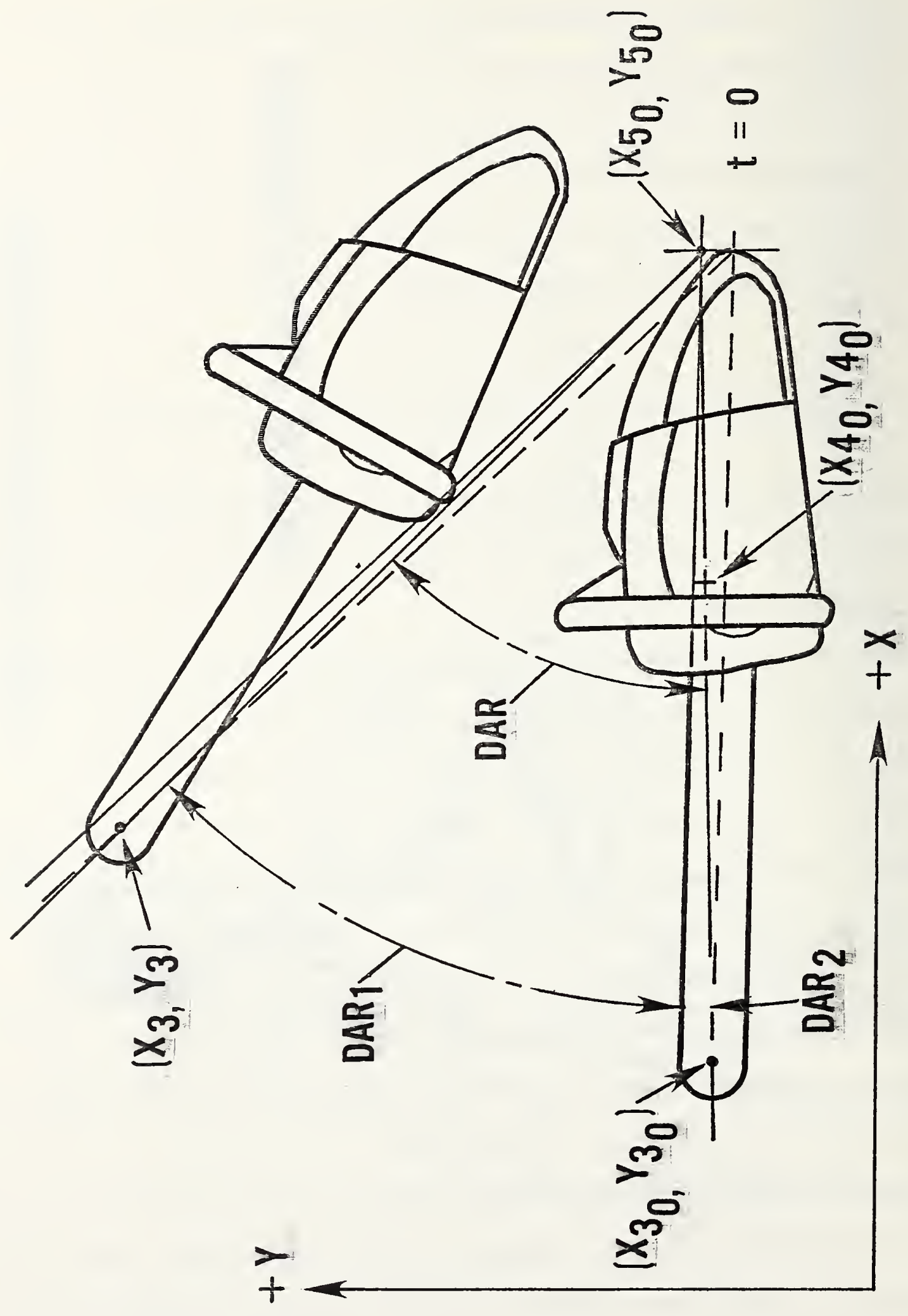

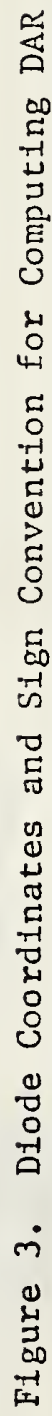


Similar corrections to the other diode positions on the guidebar, the saw, and at its center of gravity, were estimated to have a minor influence on the computed angle of rotation about the rear handle. These corrections and other second-order factors were investigated by computer analyses of the displacement data for Test Subjects $\mathrm{CDS}$ and $\mathrm{NB}$ which are given in Appendix C.

A summary of the computed DAR (derived angle of rotation), for each of the hand-held kickback tests, is given in tables 3 through 9.1 In addition to the values for DAR, the average DAR for each data set ( 5 tests) is given, along with the standard deviation and coefficient of variation. Following the same convention used in analyses of KBM kickback data, the coefficient of variation is defined as the standard deviation divided by the average value for each data set.

${ }^{1}$ There were 11 test subjects who participated in the Test Series 1 kickback tests; replicate tests for 7 of these subjects were conducted during Test Series 2 . Additional information pertaining to the subject treatment and other human factors considerations is presented in Apendix B. 
Table 3. Computed values of kickback derived angle of rotation (DAR) for Saw Gl

\begin{tabular}{|c|c|c|c|c|c|c|c|c|c|}
\hline $\begin{array}{c}\text { Test } \\
\text { Series } \\
\end{array}$ & $\begin{array}{c}\text { Test } \\
\text { Subject } \\
\end{array}$ & $\begin{array}{r}\text { DAR f } \\
1 \\
\end{array}$ & or $\mathrm{Re}$ & plica & $\mathrm{te} \mathrm{Te}$ & $\begin{array}{l}\text { ts, deg } \\
5 \\
\end{array}$ & $\begin{array}{l}\text { Average } \\
\text { DAR, deg }\end{array}$ & $\begin{array}{l}\text { Standard } \\
\text { Deviation }\end{array}$ & $\begin{array}{c}\text { Coefficient } \\
\text { of } \\
\text { Variation } \\
\end{array}$ \\
\hline \multirow[t]{11}{*}{1} & $\mathrm{CS}$ & $5 R^{1}$ & $3 R$ & $7 \mathrm{R}$ & $1 \mathrm{R}$ & $6 \mathrm{R}$ & 4.4 & 2.41 & 0.55 \\
\hline & $\mathrm{CK}$ & $7 R$ & $19 \mathrm{R}$ & $16 \mathrm{R}$ & $11 \mathrm{~F}$ & $7 F$ & 12.0 & 5.38 & 0.45 \\
\hline & $\mathrm{CR}$ & $25 R$ & $24 R$ & $7 \mathrm{R}$ & $10 \mathrm{R}$ & $15 R$ & 16.2 & 8.10 & 0.50 \\
\hline & $\mathrm{CN}$ & $16 F$ & $15 \mathrm{~F}$ & $10 F$ & $13 \mathrm{~F}$ & $10 F$ & 12.8 & 2.77 & 0.22 \\
\hline & $\mathrm{CJ}$ & $9 R$ & $21 R$ & $11 R$ & $18 \mathrm{~F}$ & $13 F$ & 14.4 & 4.97 & 0.34 \\
\hline & $C D$ & $16 \mathrm{~F}$ & $13 \mathrm{~F}$ & $17 \mathrm{~F}$ & $11 \mathrm{R}$ & $8 \mathrm{R}$ & 13.0 & 3.67 & 0.28 \\
\hline & $\mathrm{CMJ}$ & $19 F$ & $16 \mathrm{~F}$ & $15 \mathrm{~F}$ & $19 \mathrm{R}$ & $15 \mathrm{R}$ & 16.8 & 2.05 & 0.12 \\
\hline & $\mathrm{CA}$ & $44 R$ & 2 & 2 & 2 & $29 F$ & - & -- & - \\
\hline & NB & $14 R$ & $16 \mathrm{R}$ & $12 \mathrm{R}$ & $10 \mathrm{R}$ & $11 \mathrm{R}$ & 12.6 & 2.41 & 0.19 \\
\hline & CDS & $26 \mathrm{~F}$ & $27 F$ & $30 F$ & 2 & $26 \mathrm{~F}$ & 27.2 & 1.89 & 0.07 \\
\hline & CHD & $43 F$ & $18 \mathrm{~F}$ & $19 \mathrm{~F}$ & $16 \mathrm{~F}$ & $13 F$ & 21.8 & 12.07 & 0.55 \\
\hline \multirow[t]{7}{*}{2} & CDS & $24 \mathrm{~F}$ & $29 \mathrm{~F}$ & $17 \mathrm{~F}$ & $27 F$ & $20 F$ & 23.4 & 4.93 & 0.21 \\
\hline & $\mathrm{CR}$ & $22 \mathrm{~F}$ & $15 F$ & $35 \mathrm{~F}$ & $25 \mathrm{~F}$ & $18 \mathrm{~F}$ & 23.0 & 7.71 & 0.34 \\
\hline & $\mathrm{CJ}$ & $27 \mathrm{~F}$ & $35 F$ & $25 \mathrm{~F}$ & $39 F$ & $27 F$ & 30.6 & 6.07 & 0.20 \\
\hline & CHD & $26 \mathrm{R}$ & $28 \mathrm{R}$ & $23 R$ & $24 R$ & $25 R$ & 25.2 & 1.92 & 0.08 \\
\hline & $\mathrm{CN}$ & $11 \mathrm{~F}$ & $10 F$ & $14 \mathrm{~F}$ & $15 \mathrm{~F}$ & $10 F$ & 12.0 & 2.34 & 0.20 \\
\hline & NB & $17 R$ & $21 R$ & $13 \mathrm{R}$ & $18 \mathrm{R}$ & $16 \mathrm{R}$ & 17.0 & 2.92 & 0.17 \\
\hline & $C D$ & $41 R$ & $23 R$ & $25 R$ & $34 \mathrm{R}$ & 2 & 30.7 & 8.34 & 0.27 \\
\hline
\end{tabular}

Average coefficient of variation for 17 tests was 0.28 .

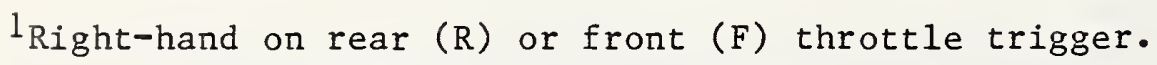

2Malfunction of recording system occurred during the test which interrupted the data transfer to the computer memory. 
Table 4. Computed values of kickback derived angle of rotation (DAR) for Saw G2

DAR for Replicate Tests, deg

Test Test

Series Subject

$1 \quad \mathrm{CS}$

CK

$\mathrm{CR}$

CN

CJ

$\mathrm{CD}$

CMJ

$\mathrm{CA}$

NB

CDS

CHD

$2 \quad \operatorname{CDS}$

CR

CJ

CHD

$\mathrm{CN}$

NB

CD

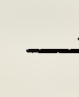

$\begin{array}{lllll}19 & 26 & 35 & 20 & 26\end{array}$

$\begin{array}{lllll}18 & 19 & 14 & 18 & 19\end{array}$

$\begin{array}{lllll}15 & 14 & 19 & 16 & 14\end{array}$

$\begin{array}{lllll}19 & 14 & 29 & 16 & 17\end{array}$

$\begin{array}{lllll}23 & 17 & 16 & 19 & 21\end{array}$

$\begin{array}{lllll}15 & 14 & 1 & 10 & 14\end{array}$

$\begin{array}{lllll}37 & 16 & 29 & 12 & 26\end{array}$

$\begin{array}{lllll}19 & 14 & 23 & 20 & 22\end{array}$

$\begin{array}{lllll}11 & 15 & 14 & 15 & 13\end{array}$

$\begin{array}{lllll}37 & 21 & 27 & 30 & 25\end{array}$

$\begin{array}{lllll}17 & 27 & 22 & 23 & 20\end{array}$

$\begin{array}{lllll}32 & 30 & 34 & 19 & 29\end{array}$

$\begin{array}{lllll}16 & 18 & 13 & 17 & 10\end{array}$

$\begin{array}{lllll}17 & 14 & 14 & 12 & 16\end{array}$

30

27

$\begin{array}{lllll}15 & 14 & 18 & 10 & 15\end{array}$

$\begin{array}{lllll}25 & 15 & 28 & 17 & 15\end{array}$

$\begin{array}{lllll}17 & 22 & 14 & 16 & 14\end{array}$
Average

DAR, deg

25.2

17.6

15.6

19.0

19.2

13.2

24.0

19.6

13.6

28.0

21.8

28.8

14.8

14.6

25.6

14.4

20.0

16.6
Coefficient of

Variation

0.25

6.38

0.12

2.07

0.13

2.07

0.31

5.87

0.15

2.86

0.17

2.22

0.42

10.07

0.18

3.51

0.12

1.67

0.21

6.00

0.17

3.70

0.20

5.80

0.22

3.27

0.13

1.95

0.15

3.78

0.20

2.88

0.30

6.08

0.20

Average coefficient of variation for 18 tests was 0.20 .

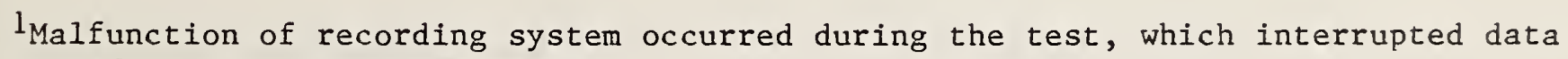
transfer to the computer memory. 
Table 5. Computed values of kickback derived angle of rotation (DAR) for Saw G3

Test DAR for Replicate Tests, deg Series Subject

\begin{tabular}{|c|c|c|c|c|c|c|c|c|c|}
\hline $\begin{array}{c}\text { Test } \\
\text { Series } \\
\end{array}$ & $\begin{array}{c}\text { Test } \\
\text { Subject } \\
\end{array}$ & DAR & or & pli & te ? & $\begin{array}{l}\text { sts, deg } \\
5 \\
\end{array}$ & $\begin{array}{l}\text { Average } \\
\text { DAR, deg }\end{array}$ & $\begin{array}{l}\text { Standard } \\
\text { Deviation } \\
\end{array}$ & $\begin{array}{c}\text { Coefficient } \\
\text { of } \\
\text { Variation } \\
\end{array}$ \\
\hline \multirow[t]{11}{*}{1} & $\mathrm{CS}$ & 22 & 10 & 17 & 28 & 24 & 20.2 & 6.94 & 0.34 \\
\hline & $\mathrm{CK}$ & 14 & 14 & 17 & 13 & 13 & 14.2 & 1.64 & 0.12 \\
\hline & $\mathrm{CR}$ & 10 & 14 & 14 & 16 & 18 & 14.4 & 2.97 & 0.21 \\
\hline & $\mathrm{CN}$ & 10 & 13 & 12 & 12 & 14 & 12.2 & 1.48 & 0.12 \\
\hline & CJ & 14 & 7 & 15 & 13 & 11 & 12.0 & 3.16 & 0.26 \\
\hline & $C D$ & 18 & 16 & 16 & 22 & 23 & 19.0 & 3.32 & 0.17 \\
\hline & $\mathrm{CMJ}$ & 18 & 14 & 30 & 24 & 20 & 21.2 & 6.10 & 0.29 \\
\hline & $\mathrm{CA}$ & 11 & 14 & 16 & 14 & 21 & 15.2 & 3.70 & 0.24 \\
\hline & NB & 12 & 8 & 11 & 14 & 11 & 11.2 & 2.17 & 0.19 \\
\hline & CDS & 20 & 17 & 23 & 31 & 32 & 24.6 & 6.65 & 0.27 \\
\hline & CHD & 23 & 21 & 26 & 22 & 20 & 22.4 & 2.30 & 0.10 \\
\hline \multirow[t]{7}{*}{2} & CDS & 32 & 41 & 26 & 27 & 26 & 30.4 & 6.43 & 0.21 \\
\hline & $\mathrm{CR}$ & 18 & 17 & 15 & 17 & 15 & 16.4 & 1.34 & 0.08 \\
\hline & CJ & 16 & 15 & 14 & 14 & 14 & 14.6 & 0.89 & 0.06 \\
\hline & CHD & 20 & 25 & 22 & 24 & 25 & 23.2 & 2.17 & 0.09 \\
\hline & $\mathrm{CN}$ & 11 & 18 & 18 & 21 & 20 & 17.6 & 3.91 & 0.22 \\
\hline & $\mathrm{NB}$ & 21 & 23 & 16 & 18 & 12 & 18.0 & 4.30 & 0.24 \\
\hline & $C D$ & 16 & 17 & 23 & 22 & 22 & 20.0 & 3.24 & 0.16 \\
\hline
\end{tabular}

Coefficient

Average Standard of DAR, deg Deviation Variation 20.2

Average coefficient of variation for 18 tests was 0.19 . 
Table 6. Computed values of kickback derived angle of rotation (DAR) for Saw G4

DAR for Replicate Tests, deg

Test Test

Series Subject

\begin{tabular}{lllll}
1 & 2 & 3 & 4 & 5 \\
\hline
\end{tabular}

Average Standard

Coefficient

DAR,deg Deviation Variation

1

CS

$\begin{array}{lllll}39 & 34 & 31 & 24 & 26\end{array}$

30.8

6.06

0.20

CK

$\begin{array}{lllll}15 & 14 & 14 & 18 & 15\end{array}$

15.2

1.64

0.11

CR

$41 \quad 40 \quad 30 \quad 34 \quad 44$

37.8

5.67

0.15

$\mathrm{CN}$

$\begin{array}{lllll}35 & 41 & 33 & 29 & 41\end{array}$

35.8

5.22

0.14

CJ

$\begin{array}{lllll}32 & 24 & 23 & 24 & 30\end{array}$

26.6

$4 \cdot 10$

0.15

CD

$\begin{array}{lllll}25 & 18 & 26 & 30 & 34\end{array}$

26.6

5.98

0.22

CMJ

$\begin{array}{lllll}48 & 28 & 32 & 34 & 28\end{array}$

34.0

8.25

0.24

CA

$\begin{array}{lllll}36 & 36 & 36 & 24 & 41\end{array}$

34.6

6.31

0.18

NB

$\begin{array}{lllll}39 & 37 & 44 & 41 & 31\end{array}$

38.4

4.88

0.13

CDS

$52^{1} \quad 49 \quad 36 \quad 36 \quad 51^{1}$

44.8

8.10

0.18

CHD

$\begin{array}{lllll}39 & 32 & 40 & 33 & 36\end{array}$

36.0

3.54

0.10

2

CDS

$\begin{array}{lllll}50^{1} & 52^{1} & 30 & 35 & 43\end{array}$

42.0

9.46

0.22

CR

$\begin{array}{lllll}28 & 46 & 38 & 26 & 48^{1}\end{array}$

37.2

10.06

0.27

CJ

$\begin{array}{lllll}31 & 35 & 33 & 31 & 32\end{array}$

32.4

1.67

0.05

CHD

$\begin{array}{lllll}41 & 38 & 45 & 47 & 33\end{array}$

40.8

5.58

0.14

$\mathrm{CN}$

$\begin{array}{lllll}41 & 38 & 34 & 38 & 32\end{array}$

36.6

3.58

0.10

NB

$\begin{array}{lllll}48 & 46 & 34 & 41 & 35\end{array}$

40.8

6.30

0.15

CD

$\begin{array}{lllll}2 & 24 & 34 & 20 & 25\end{array}$

25.8

5.91

0.23

Average coefficient of variation for 18 tests was 0.16 .

${ }^{1}$ Saw struck safety bar.

2 Malfunction of recording system occurred during the test, which interrupted the data transfer to the computer memory. 
Table 7. Computed values of kickback derived angle of rotation (DAR) for Saw G5

DAR for Replicate Tests, deg

Test Test

Series Subject

$$
1
$$

CS

CK

CR

CN

CJ

$\mathrm{CD}$

CMJ

$\mathrm{CA}$

NB

CDS

CHD

2 CDS

$\mathrm{CR}$

CJ

CHD

CN

NB

$C D$

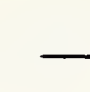

1

$\begin{array}{lllll}8 & 16 & 13 & 10 & 19\end{array}$

$\begin{array}{lllll}25 & 25 & 25 & 23 & 12\end{array}$

$\begin{array}{lllll}33 & 36 & 38 & 34 & 37\end{array}$

$\begin{array}{lllll}46 & 47 & 45 & 38 & 34\end{array}$

$\begin{array}{lllll}32 & 27 & 18 & 20 & 24\end{array}$

$\begin{array}{lllll}15 & 16 & 37 & 9 & 16\end{array}$

$\begin{array}{lllll}23 & 13 & 16 & 22 & 15\end{array}$

$\begin{array}{lllll}37 & 30 & 25 & 25 & 29\end{array}$

$21 \quad 51^{1} \quad 43 \quad 35 \quad 22$

$\begin{array}{lllll}47 & 32 & 51^{1} & 49^{1} & 48\end{array}$

$\begin{array}{lllll}42 & 26 & 29 & 41 & 30\end{array}$

$49^{1} \quad 49^{1} \quad 51^{1} \quad 52^{1} \quad 47$

$\begin{array}{lllll}41 & 42 & 34 & 32 & 28\end{array}$

$\begin{array}{lllll}32 & 37 & 35 & 47 & 36\end{array}$

$\begin{array}{lllll}41 & 42 & 49 & 42 & 37\end{array}$

$\begin{array}{lllll}39 & 45 & 36 & 28 & 25\end{array}$

$\begin{array}{lllll}53 & 57 & 32 & 45 & 28\end{array}$

$\begin{array}{lllll}18 & 33 & 14 & 22 & 24\end{array}$
Average

DAR, deg

13.2

22.0

35.6

42.0

24.2

18.6

17.8

29.2

34.4

45.4

33.6

49.6

35.4

37.4

42.2

34.6

43.0

22.2
Coefficient of

Standard Deviation

$$
4.44
$$

0.34

5.66

0.26

2.07

0.06

5.70

0.14

5.58

0.23

10.69

0.57

4.44

0.25

4.92

0.17

13.07

0.38

7.64

0.17

7.37

0.22

1.95

0.04

5.98

0.17

5.68

0.15

4.32

0.10

8.14

0.24

12.71

0.30

7.16

0.32

Average coefficient of variation for 18 tests was 0.23 .

${ }^{1}$ Saw struck safety bar. 
Table 8. Computed values of kickback derived angle of rotation (DAR) for Saw E6

\begin{tabular}{|c|c|c|c|c|c|c|c|c|c|}
\hline $\begin{array}{c}\text { Test } \\
\text { Series } \\
\end{array}$ & $\begin{array}{c}\text { Test } \\
\text { Subject } \\
\end{array}$ & DAR & or 1 & plic & te ? & $\begin{array}{l}\text { sts, deg } \\
5 \\
\end{array}$ & $\begin{array}{l}\text { Average } \\
\text { DAR, deg } \\
\end{array}$ & $\begin{array}{l}\text { Standard } \\
\text { Deviation } \\
\end{array}$ & $\begin{array}{c}\text { Coefficient } \\
\text { of } \\
\text { Variation } \\
\end{array}$ \\
\hline \multirow[t]{11}{*}{1} & $\mathrm{CS}$ & 7 & 12 & 9 & 13 & 12 & 10.6 & 2.52 & 0.24 \\
\hline & $\mathrm{CK}$ & 5 & 2 & 3 & 4 & 4 & 3.6 & 1.14 & 0.32 \\
\hline & $\mathrm{CR}$ & 10 & 8 & 7 & 8 & 9 & 8.4 & 1.14 & 0.14 \\
\hline & $\mathrm{CN}$ & 6 & 7 & 14 & 10 & 11 & 9.6 & 3.21 & 0.33 \\
\hline & $\mathrm{CJ}$ & 6 & 13 & 12 & 13 & 11 & 11.0 & 2.92 & 0.26 \\
\hline & $C D$ & 22 & 16 & 18 & 14 & 23 & 18.6 & 3.85 & 0.21 \\
\hline & $\mathrm{CMJ}$ & 17 & 27 & 26 & 29 & 17 & 23.2 & 5.76 & 0.25 \\
\hline & $\mathrm{CA}$ & 18 & 26 & 16 & 16 & 27 & 20.6 & 5.46 & 0.26 \\
\hline & NB & 9 & 10 & 10 & 8 & 13 & 10.0 & 1.87 & 0.19 \\
\hline & CDS & 21 & 22 & 26 & 26 & 22 & 23.4 & 2.41 & 0.10 \\
\hline & CHD & 9 & 7 & 7 & 18 & 17 & 11.6 & 5.46 & 0.47 \\
\hline \multirow[t]{7}{*}{2} & CDS & 17 & 16 & 19 & 16 & 18 & 17.2 & 1.30 & 0.08 \\
\hline & $\mathrm{CR}$ & 15 & 8 & 9 & 10 & 10 & 10.4 & 2.70 & 0.26 \\
\hline & $\mathrm{CJ}$ & 13 & 14 & 13 & 13 & 11 & 12.8 & 1.10 & 0.08 \\
\hline & CHD & 23 & 18 & 22 & 16 & 14 & 18.6 & 3.85 & 0.21 \\
\hline & $\mathrm{CN}$ & 9 & 10 & 10 & 7 & 12 & 9.6 & 1.82 & 0.19 \\
\hline & NB & 16 & 18 & 15 & 19 & 11 & 15.8 & 3.11 & 0.20 \\
\hline & $C D$ & 12 & 15 & 16 & 20 & 12 & 15.0 & 3.32 & 0.22 \\
\hline
\end{tabular}

Average coefficient of variation for 18 tests was 0.22 . 
Table 9. Computed values of kickback derived angle of rotation (DAR) for Saw E7

DAR for Replicate Tests, deg

Series Subject

1

1

1

$\begin{array}{rrrrrr}\mathrm{CK} & 10 & 13 & 35 & 9 & 10 \\ \mathrm{CR} & 8 & 8 & 8 & 10 & 12\end{array}$

CS

CR

CN

CJ

$C D$

CMJ

$\mathrm{CA}$

NB

CDS

CHD

2

$\begin{array}{llllll}\text { CDS } & 11 & 20 & 21 & 11 & 17 \\ C R & 7 & 12 & 10 & 12 & 7\end{array}$

CR

CJ

CHD

$\mathrm{CN}$

NB

CD

$\begin{array}{lllll}13 & 10 & 11 & 10 & 15\end{array}$

$\begin{array}{lllll}12 & 11 & 15 & 10 & 8\end{array}$

$\begin{array}{lllll}21 & 18 & 14 & 15 & 14\end{array}$

$\begin{array}{lllll}25 & 12 & 16 & 16 & 14\end{array}$

$\begin{array}{lllll}27 & 42 & 27 & 1 & 1\end{array}$

$\begin{array}{lllll}18 & 32 & 24 & 8 & 10\end{array}$

$\begin{array}{lllll}14 & 14 & 18 & 13 & 31\end{array}$

$\begin{array}{lllll}15 & 9 & 16 & 14 & 13\end{array}$

$\begin{array}{lllll}12 & 12 & 16 & 9 & 15\end{array}$

$\begin{array}{lllll}27 & 23 & 17 & 19 & 18\end{array}$

$\begin{array}{lllll}9 & 7 & 12 & 20 & 9\end{array}$

$\begin{array}{lllll}6 & 8 & 10 & 14 & 10\end{array}$

$\begin{array}{lllll}21 & 28 & 14 & 31 & 42\end{array}$ $\begin{array}{lllll}7 & 12 & 10 & 12 & 7\end{array}$
Average Standard

DAR, deg Deviation

17.0

7.11

11.06

1.79

2.17

2.59

3.05

4.98

8.66

9.94

7.52

2.70

4.80

2.51

2.77

4.15

5.13

2.97

10.57

27.2
Coefficient of Variation

0.42

0.72

0.19

0.18

0.23

0.18

0.30

0.27

0.54

0.42

0.20

0.30

0.26

0.22

0.20

0.45

0.31

0.39

Average coefficient of variation for 18 tests was 0.32 .

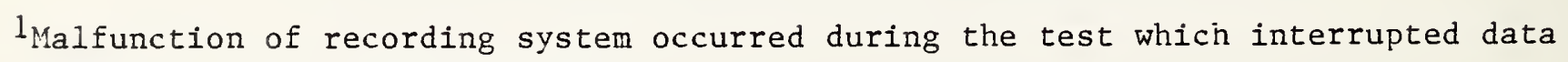
transfer to the computer memory. 


\section{Principal Test Results}

\subsection{Kickback Energy During Hand-Held Tests}

One of the principal objectives in the experimental program was to relate the kickback angle through which a chain saw might travel when held by an operator to the kickback energy determined for the saw in the Kickback Test Machine (KBM). Since the test conditions during the hand-held kickbacks were based on KBM energy data, it was desirable to determine as well as possible the kinetic energy achieved during the hand-held kickback tests. It should be emphasized that the accuracy of conclusions drawn from kinematic studies of motion depends heavily upon the accuracy of the displacement measurements which are the precursors for calculation of such quantities as the energy [4].

An initial attempt, using high-speed photography, was made to estimate the kickback energy for a hand-held saw based on evaluating the saw displacements for a kickback filmed at a speed of 300 frames per second. This estimate did not compare well with the energy determined for that saw during a simulated kickback in the KBM under the same test conditions. The major sources of inaccuracy were the relatively slow frame speed and the difficulty in visually analyzing the data from film. It was also recognized that the very small displacements associated with the initial kickback motion of the test saw center of gravity made the estimation of lateral and vertical energy components difficult without sophisticated measurement and analysis of the saw powerhead motion. Although a better estimate of the rotational energy component for a test saw was achieved by filming a kickback at a speed of 500 frames per second, the estination of the other energy components was not greatly enhanced. As noted by other investigators, attempts to calculate velocities (required to determine the energy) by differentiation of displacements have been plagued by amplification of the noise inherent in even apparently smooth displacement data [4] 
The use of an optoelectronic system for measuring the kickback motion in the present experimental program permitted a more reliable estimate to be made for the rotational energy for some kickback tests. The source of error due to visual analysis of film is eliminated, but the noise associated with very small displacements of the saw powerhead was not greatly improved. The standard sampling rate of 312 $\mathrm{Hz}$ for the optoelectronic measuring system was sufficient to enable good estinates to be made for saw rotational velocities, at least for the test saws having large kickback motion when held by relaxed test subjects. Attempts made to increase the standard sampling rate were unsuccessful due to the inability to multiplex the number of LED positions required.

The estimates of rotational energy for each of the test saws and the rotational energy obtained with the KBM for the saws at the same test conditions are given in table 10. The values in this table were computed for test conditions where the duration of the kickback per degree of rotation indicated that the test subject was relatively relaxed.5 In this regard, it is evident that a large amount of energy can be absorbed if the saw motion deviates from a planar path (planar motion is ensured in the KBM by constraint of a test saw). Thus, the estimates of rotational energy are in best agreement with the known energy values when the test subject does not impose constraints on the rotational motion of the saw that differ substantially from those in the KBM.

${ }^{5}$ Typical values for this index found by a major saw manufacturer were in the range of 0.002 to $0.005 \mathrm{sec}$ per degree. 
Table 10. Estimated rotational kickback energy for saws during hand-held tests.

\begin{tabular}{crcrr} 
Test Saw & $\begin{array}{r}\text { Rotational Energy } \\
\text { Determined in KBM } \\
\text { joule (in-lbf) }\end{array}$ & \multicolumn{2}{c}{$\begin{array}{r}\text { Estimated Rotational } \\
\text { Energy in Hand-Held Tests } 1 \\
\text { joule (in-lbf) }\end{array}$} \\
\hline G1 & 9.5 & $(84)$ & 6.8 & $(60)$ \\
G2 & 11.1 & $(98)$ & 8.4 & $(74)$ \\
G3 & 9.7 & $(86)$ & 8.4 & $(74)$ \\
G4 & 32.5 & $(288)$ & 27.0 & $(239)$ \\
G5 & 46.7 & $(413)$ & 42.1 & $(373)$ \\
E6 & 8.6 & $(76)$ & 7.6 & $(67)$ \\
E7 & 7.6 & $(67)$ & 7.2 & $(64)$
\end{tabular}

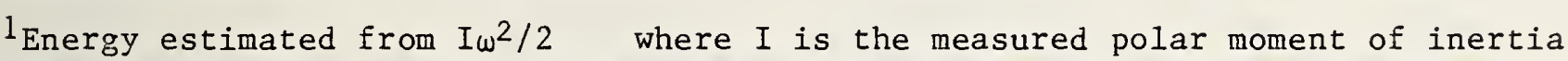
about the saw c.g. and $\omega$ is the maximum rotational velocity determined from optoelectronic displacement data. The velocity was estimated during the initial kickback motion (while the chain was in contact with the wood specimen) and only the inertia due to the saw was considered. 
6.2 Comparison of Saw Motion with Energy Measured in Kickback Machine In order to compare the chain saw rotational motion measured during the handheld kickback tests with the energy measured for the test saws in the kickback machine, it is useful to average the computed kickback angles. The average and maximum values for the derived angle of rotation (DAR) for each test subject and saw are presented in tables 11 and 12 for the first 11 kickback tests (Test Series 1) and the last 7 tests (Test Series 2), respectively. A tabulation of the composite mean and maximum DAR values for Test Series 1 and 2 is given in table 13. Comparison of the Series 1 and 2 data in the latter table indicates there was probably some effect from subjects learning on saw kickback, particularly for saws G1, G4 and G5. The total kickback energy and rotational components of energy for the test saws determined using the kickback machine are given in the last column of the table. 
Table 11. Summary of average and maximum values of derived angle of rotation (DAR) for kickback test series 1 .

$$
\text { DAR, deg }
$$

Test Subject Kickback Angle

CS

CS

CK

CK

CR

CR

CN

CN

CJ

CJ

CD

CD

CMJ

CMJ

CA

CA

NB

NB

CDS

CDS

CHD

CHD
Average

Maximum

Average

Maximum

Average

Maximum

Average

Maximun

Average

Maximum

Average

Maximum

Average

Maximum

Average

Maximum

Average

Maximum

Average

Maximum

Average

Maximum

\section{$\underline{G}$}

$4 \quad 25 \quad 20 \quad 31$

$\begin{array}{lll}7 & 35 & 28\end{array}$

39

1218

1919

$16 \quad 16$

2519

1319

$16 \quad 29$

$\begin{array}{lll}14 & 19 & 12\end{array}$

$\begin{array}{lll}21 & 23 & 15\end{array}$

$\begin{array}{lll}13 & 13 & 19\end{array}$

$17 \quad 15$

$17 \quad 24$

$\begin{array}{lll}19 & 37 & 30\end{array}$

$\begin{array}{llll}48 & 23 & 29 & 25\end{array}$

$\begin{array}{lllllll}1 & 20 & 15 & 35 & 29 & 21 & 32\end{array}$

$\begin{array}{lllllll}44 & 23 & 21 & 41 & 37 & 27 & 42\end{array}$

$\begin{array}{lllllll}13 & 14 & 11 & 38 & 34 & 10 & 18\end{array}$

$\begin{array}{lllllll}16 & 15 & 14 & 44 & 51 & 13 & 32\end{array}$

$\begin{array}{lllllll}27 & 28 & 25 & 45 & 45 & 23 & 18\end{array}$

$\begin{array}{lllllll}30 & 37 & 32 & 52 & 51 & 26 & 31\end{array}$

$\begin{array}{lllllll}22 & 22 & 22 & 36 & 34 & 12 & 13\end{array}$

$\begin{array}{lllllll}43 & 27 & 26 & 40 & 42 & 18 & 16\end{array}$

${ }^{1}$ Insufficient data to compute average DAR. 
Table 12. Summary of average and maximum values of derived angle of rotation (DAR) for kickback test series 2 .

$\mathrm{DAR}$, deg

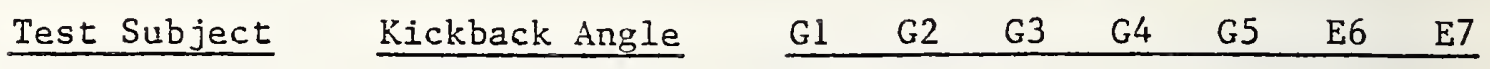

CDS

CDS

CR

CR

CJ

CJ

CHD

CHD

CN

$\mathrm{CN}$

NB

NB

$C D$

CD
Average

Maximum

Average

Maximum

Average

Maximum

Average

Maximum

Average

Maximum

Average

Maximum

Average

Maximum $\begin{array}{lllllll}23 & 29 & 30 & 42 & 50 & 17 & 16\end{array}$

$\begin{array}{lllllll}29 & 34 & 41 & 52 & 52 & 19 & 21\end{array}$

$\begin{array}{lllllll}23 & 15 & 16 & 37 & 35 & 10 & 10\end{array}$

$\begin{array}{lllllll}35 & 18 & 18 & 48 & 42 & 15 & 12\end{array}$

$\begin{array}{lllllll}31 & 15 & 15 & 32 & 37 & 13 & 13\end{array}$

$\begin{array}{lllllll}39 & 17 & 16 & 35 & 47 & 14 & 16\end{array}$

$\begin{array}{lllllll}25 & 26 & 23 & 41 & 42 & 19 & 21\end{array}$

$\begin{array}{lllllll}28 & 30 & 25 & 47 & 49 & 23 & 27\end{array}$

$\begin{array}{lllllll}12 & 14 & 18 & 37 & 35 & 10 & 11\end{array}$

$\begin{array}{lllllll}15 & 18 & 21 & 41 & 45 & 12 & 20\end{array}$

$\begin{array}{lllllll}17 & 20 & 18 & 41 & 43 & 16 & 10\end{array}$

$\begin{array}{lllllll}21 & 28 & 23 & 48 & 57 & 19 & 14\end{array}$

$\begin{array}{lllllll}31 & 17 & 20 & 26 & 22 & 15 & 27\end{array}$

$\begin{array}{lllllll}41 & 22 & 23 & 34 & 33 & 20 & 42\end{array}$ 
Table 13. Comparison of average and maximum values of derived angles of rotation for Kickback Test Series 1, Series 2, and combined test series with energy determined in Kickback Machine (KBM) ${ }^{1}$.

Test Series Test Series Combined

$\frac{1}{\text { Avg. Max. }} \frac{2}{\text { Avg. Max. }} \quad \frac{\text { Test Series }}{\text { Avg } \bullet \text { Max. }}$

Test DAR DAR DAR DAR DAR DAR 2 Total Energy Energy

$\underline{\text { Saw }}$ (deg) (deg) (deg) (deg) (deg) (deg) joule (in-lbf) joule (in-lbf)

$\begin{array}{lllllllllll}\text { G1 } & 15 & 23 & 23 & 30 & 18 & 26 & 12.6 & (112) & 9.5 & (84) \\ \text { G2 } & 20 & 25 & 19 & 24 & 20 & 25 & 13.6 & (120) & 11.1 & (98) \\ \text { G3 } & 17 & 22 & 20 & 24 & 18 & 22 & 10.7 & (95) & 9.7 & (86) \\ \text { G4 } & 33 & 39 & 36 & 44 & 34 & 41 & 36.3 & (321) & 32.5 & (288) \\ \text { G5 } & 29 & 36 & 38 & 46 & 32 & 40 & 51.8 & (458) & 46.7 & (413) \\ \text { E6 } & 14 & 17 & 14 & 17 & 14 & 17 & 9.6 & (85) & 8.6 & (76) \\ \text { E7 } & 16 & 24 & 15 & 22 & 16 & 23 & 11.9 & (105) & 7.6 & (67)\end{array}$

Avg.

Coef. of

Variation 0.25

0.20

0.23

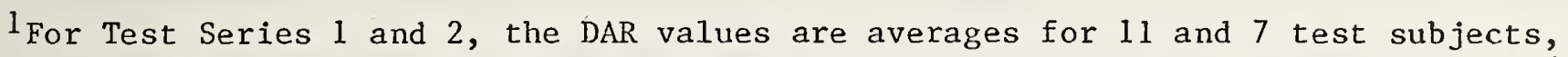
respectively. For the combined test series, the DAR values are for 18 subjects ( 11 test subjects with replicate tests for 7 of these during Series 2).

2 The maximum DAR values denote the mean of the largest derived angles of rotation for the respective test series.

\subsection{Evaluation of Low Kickback Energy Chain}

At the request of the CPSC, an extra set of hand-held kickback tests were conducted for three test subjects to evaluate a specially designed saw chain. In the last few years, several chain manufacturers have developed saw chains designed to reduce the kickback energy potential for some types of consumer chain saws. A series of kickback tests had been performed during earlier tests with the KBM in which one of these "low energy" chains was compared with a standard-type chain for test saw G5 [1]. 
A similar set of hand-held kickback tests were conducted using the low energy chain as well as the original equipment chain for saw G5. Since these two chains were identical to the chain used in the evaluation of kickback energy determined with the KBM, it was possible to compare the reduction in kickback for the low energy chain in terms of kickback derived angle of rotation as well as in terms of kickback energy. The results of kickback tests in the KBM and during the hand-held tests for the two chain designs are sumarized in table 14.

Table 14. Comparison of kickback tests using original equipment (0) and low energy ( $L$ ) chain for Saw G5.

\begin{tabular}{|c|c|c|c|c|c|}
\hline \multirow[b]{2}{*}{ Kickback Test } & \multirow{2}{*}{$\begin{array}{l}\text { Average } \\
\text { Chain } 0 \\
\end{array}$} & \multirow{2}{*}{$\begin{array}{c}\text { DAR, deg } \\
\text { Chain L } \\
\end{array}$} & \multicolumn{2}{|c|}{$\begin{array}{l}\text { Total Energy } \\
\text { joule (in-lbf) }\end{array}$} & \multirow{2}{*}{$\begin{array}{c}\text { Reduction in } \\
\text { Kickback, } \\
\text { percent }\end{array}$} \\
\hline & & & Chain 0 & Chain L & \\
\hline Hand-held (Subject CDS) & 50 & 11 & - & - & 78 \\
\hline (Subject CR) & 35 & 5 & - & - & 86 \\
\hline (Subject CJ) & 37 & 7 & - & - & $81^{\circ}$ \\
\hline Kickback Machine & - & - & $53.0(469)$ & $14.9(132)$ & 72 \\
\hline
\end{tabular}

${ }^{1}$ Percent Reduction in Kickback $=\frac{\text { Kickback for Chain } 0-\text { Kickback for Chain L }}{\text { Kickback for Chain } 0} 100$ 


\subsection{Evaluation of Handle Spacing Effect on Saw Motion}

Test Saw G1 was unique among the saws used in the hand-held kickback program in that it had two throttle trigger locations on the rear handle. The forwardmost trigger was located approximately $5 \mathrm{~cm}$ (2 in) from the saw front handle, and the rearmost trigger was located $16 \mathrm{~cm}(6.5 \mathrm{in})$ from the front handle, measured along a line parallel to the flat portion of the guidebar. Due to this trigger arrangement, it was possible to investigate the influence of handle spacing on the motion of Saw Gl during the hand-held kickback tests.

To facilitate an unbiased determination of the handle spacing effect, the replicate tests for Saw Gl were arranged so that some test subjects gripped only the front throttle trigger, some gripped only the rear trigger, and some subjects alternated the trigger they gripped for the replicate tests. 6 A summary of the derived angles of rotation for the Test Series 1 and 2 for Saw Gl, using the two right-hand grip positions, are given in table 15. The throttle trigger gripped for each kickback test is noted in the table by the symbols $F$ (forward throttle) and $R$ (rear throttle). The average DAR when the subject gripped the rear throttle trigger was $17.6 \mathrm{deg}$; when the subject gripped the front throttle trigger, the average DAR was $19.5 \mathrm{deg}$. Although the differences in the average DAR for the two righthand grip positions is not large, it is in the direction which was expected since the operator's hands are closer together when the front trigger is gripped.

6 The random match for the replicate tests was provided by the CPSC and is discussed in Appendix B. 
Table 15. Derived angles of rotation for kickback tests with Saw GI for two rear handle grip positions.

\section{Test Series}

1

2

\section{Test Subject}

CS

CK

CR

CN

CJ

CD

CMJ

CA

NB

CDS

CHD

$\operatorname{CDS}$

CR

CJ

CHD

$\mathrm{CN}$

NB

CD

Test 1

$5(\mathrm{R})$

7 (R)

25(R)

16(F)

9 (R)

16(F)

19(F)

44(R)

14 (R)

26(F)

43(F)

$24(F)$

22(F)

27 (F)

26(R)

9 (F)

$17(\mathrm{R})$

41(R)
Derived Angle of Rotation, deg

\begin{tabular}{|c|c|c|c|}
\hline Test 2 & Test 3 & Test 4 & Test 5 \\
\hline $3(R)$ & $7(\mathrm{R})$ & $1(R)$ & $6(R)$ \\
\hline $19(R)$ & $16(R)$ & $11(F)$ & $7(F)$ \\
\hline $24(R)$ & $7(R)$ & $10(R)$ & $15(R)$ \\
\hline $15(F)$ & $10(F)$ & $13(F)$ & $10(F)$ \\
\hline $21(R)$ & $11(R)$ & $18(F)$ & $13(F)$ \\
\hline $13(F)$ & $17(F)$ & $11(R)$ & $8(R)$ \\
\hline
\end{tabular}

$16(F) \quad 15(F) \quad 19(R) \quad 15(R)$

1

$29(\mathrm{~F})$

$11(R)$

$16(\mathrm{R})$

$12(R)$

$10(R)$

$26(F)$

$27(\mathrm{~F}) \quad 30(\mathrm{~F})$

1

13(F)

$$
18(\mathrm{~F})
$$

$19(\mathrm{~F})$

$16(F)$

$20(\mathrm{~F})$

$29(F)$

$17(\mathrm{~F})$

$27(F)$

$18(\mathrm{R})$

$$
15(\mathrm{~F})
$$

$35(R)$

25(R)

$27(F)$

35(F) $25(\mathrm{~F}) \quad 39(\mathrm{~F})$

25(R)

$28(R) \quad 23(R) \quad 24(R)$

$10(\mathrm{~F})$

$10(\mathrm{~F}) \quad 14(\mathrm{~F}) \quad 15(\mathrm{~F})$

$16(R)$

$21(R)$

$13(R)$

$18(R)$

1

(F) - Subject gripped front throttle trigger.

(R) - Subject gripped rear throttle trigger.

$I_{\text {Malfunction of recording system occurred during test. }}$ 


\section{Discussion}

The preceding sections of this report describe the experimental program deve1oped to determine the relationship between kickback energy and chain saw motion during hand-held kickbacks for selected samples of consumer-type chain saws and volunteer test subjects. The parameter selected to characterize the saw motion was the derived or apparent angle of rotation as defined from in-depth investigation analyses of chain saw accidents by the CPSC. For each of the test subjects, significant differences were found in both average and maximum angles of rotation among the sample of saws which they held during simulated kickback.

A computer-controlled optoelectronic system employed for measuring the displacements in real time, at selected locations on the test saws, was required to determine the saw positions throughout a simulated kickback. The computer analyses of the large amount of displacement-time data required to define the path of a chain saw during kickback demonstrated several advantages of this measurement system compared to high-speed cinematography. Visual analyses for the latter are both time-consuming and suceptible to human error. ${ }^{7}$ The analyses of digitized data with a computer obviate the need for visual procedures to define the saw position over small time increments which characterize a kickback event. Furthermore, since the coordinate-time data are measured in digital form, additional kinematic parameters are easily computed. An example of this feature is given in Appendix $C$, in which the chain saw rotations for two test subjects were computed using three different reference systems. Such analyses permit a more thorough assessment to be made of the potential hazards to a chain saw operator in the absence of quantitative kickback data in a "field" situation.

\footnotetext{
${ }^{7}$ Reference [5] provides an additional critique of film techniques to collect kinematic data.
} 
A coefficient of variation for the computed angles of kickback rotation, i.e., the standard deviation divided by the mean value for five replicate tests, was chosen as an index of the test variability. For Test Series 1 and 2, the overall coefficient of variation for all test subjects and saws was 0.25 and 0.20 , respectively. This result is comparable to the same measure of repeatability characteristic of the kickback data obtained with the KBM, particularly when the orders of magnitude for the rotation angle and the kickback energy are compared [1].

Analyses of the hand-held kickback data clearly indicate that the test arrangement and procedures for the experimental program resulted in saw motion data which were both repeatable and discriminating. Thus, it is possible to compare the derived angles of rotation with the energy data, which is required for CPSC injury reduction studies [3]. The large reduction in the derived angle of rotation for Saw G5 when equipped with a low kickback energy chain, compared to the original equipment chain, tends to confirm the known reduction in kickback energy for the same saw and chain combinations when evaluated in the KBM using the corresponding test parameters. In a special investigation for Saw Gl it was found that the effect of handle spacing on the saw kickback motion was not large, but indicated that larger handle spacing tended to reduce the angle of rotation as would be expected based on consideration of mechanical principles.

Procedures for the simulation of hand-held kickbacks other than those used in this investigation might have achieved larger chain saw motion, but also might have posed greater risks to the volunteer operators and/or introduced greater test variability. In this regard, it should be noted that, during kickback tests for three operators who held either of two saws, the shielded guidebar struck the safety bar which limited the saw rotation--in some cases, with considerable impact force.1

\footnotetext{
1 The safety precautions developed for the experimental program were designed specifically for this type of contingency (see Appendix A).
} 
Thus, the average and peak angles of rotation for these tests, which are noted in the report, represent conservative values. It can be expected that the additional test saw inertia due to use of the guidebar shields would also tend to reduce the saw motion compared to that encountered in a "field" situation during a kickback event.

\section{Acknowledgments}

The assistance of Messrs. J. Huckeba and H. Kratz in conducting the experimental program and construction of the test apparatus, respectively; is gratefully acknowledged. Dr. A. Dainis and Mr. D. Brenner provided valuable assistance in the operation of the optoelectronic measurement equipment and interfacing of the latter with a high-speed computer. Mr. H. Lucas of the Consumer Product Safety Commission provided useful information throughout the experimental program; is. V. Brown and Ms. L. Santelli of the CPSC provided valuable assistance in the human factors and data analysis aspects of the program, respectively. Dr. H. P. Van Cott, Bio- . Technology, Inc., served as a human factors consultant; his recommendations for the experimental design are summarized in Appendix $B$. 


\section{References}

1. Robinson, D.C. Assessment of the kickback energy potential for chain saws. Nat. Bur. Stand. (U.S.) NBSIR 81-2193, 1981 January. 49 p.

2. Robinsor, D. C.; Huckeba, J. A. Evaluation of a human factors robotic device for simulation of chain saw kickback. Nat. Bur. Stand. (U.S.) NBSIR (in preparation).

3. Newman, R. Overview of chain saw related injuries. Consumer Product Safety Commission Epideniology Report; 1981 August.

4. Pezzack, J. C., et al. An assessment of derivative determining techniques used for motion analysis, J. Biomechanics, 10, (5/6); 1977.

5. Engin, A. E. On the biomechanics of major articulating human joints, in Progress in bionechanics, N. Akkas, (ed.). NATO Advanced Study Institutes. Series E: Applied Science (32); 1979. 
Appendix A. Development of Test Protocol

\section{Test Stand Arrangement}

In order to develop the test protocol for conducting hand-held chain saw kickback tests, it was first necessary to fabricate a test stand to assist in controlling specific test parameters and test-subject variability. Since the hand-held kickback data were required to establish the relationship between the energy determined when using the Kickback Test Machine (KBM) and kickback angle, the test stand was arranged to simulate a kickback in the same manner as for the KBM [1].

For the hand-held tests, a volunteer operator held an operating chain saw so that the guidebar was aligned in a horizontal position. Detailed procedures required to accomplish this in a safe manner are described later. The method for initiating a kickback during hand-held tests was identical to the procedure developed for the KBM; i.e., a fiberboard test specimen, clamped to

a carriage assembly, was brought into contact with the moving chain at the upper quadrant of the test saw guidebar nose. The principal change in the handheld test arrangement was the necessity for covering the straight portion of the guidebar with a shield to protect the saw operator. The shields were made as light in weight as possible to minimize their inertia. The carriage horizontal motion was controlled by a pair of horizontal rails to which the carriage was attached by four low-friction linear bearings. The carriage, which weighed $6.08 \mathrm{~kg}(13.401 \mathrm{bm})$, was accelerated by a weight falling inside a vertically mounted tube; the carriage assembly is shown in figure A. 1 . 


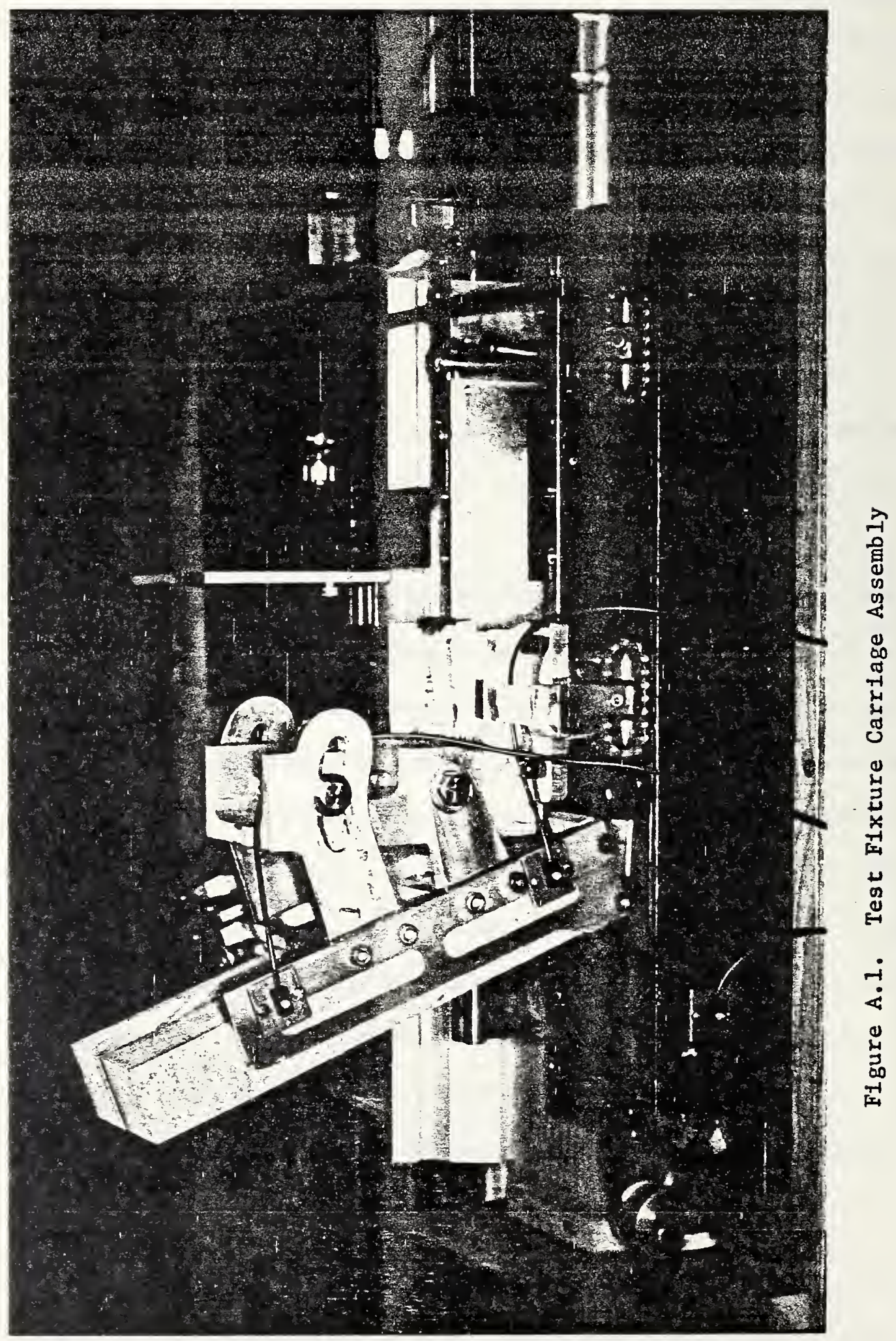


Protocol for Initiation of Chain Saw Kickback

In the Kickback Test Machine, a kickback is initiated by guiding a low friction carriage, holding a fiberboard specimen, along a guiderail into the upper nose quadrant of a clamped chain saw. The guidebar of the test saw is aligned in a horizontal position and the saw is free to rotate about its center of gravity following contact of the wood specimen with the guidebar. The carriage design features in this arrangement include: 1) acceleration of the carriage by means of a falling weight to achieve the desired approach speed, after which the weight is bottomed to permit the carriage to maintain the desired speed just prior to contact of the wood specimen with the saw guidebar; 2) an adjustable clamping assembly to permit the wood specimen angle to be adjusted relative to the initial horizontal position of the test saw guidebar; and 3) provision for the addition of weights so that the carriage weight can be adjusted (the latter is a requirement in the test protocol for the KBM).

In the test arrangement for the hand-held kickbacks, all of the principal features of the KBM carriage were reproduced in order to enable the results of the hand-held kickbacks to be correlated with data obtained with the KBM without introducing additional test carriage variables. In lieu of the instrumentation for the KBM, a photocell device was used to record the approach velocity of the carriage, which is an important test parameter.

\section{Rationale for Kickback Initiation Procedure}

The procedure for initiating kickback in the KBM requires that the wood test specimen be guided at a preselected constant velocity into the upper nose quadrant of a motionless chain saw. The saw is positioned so its guidebar is horizontal and precautions are taken in the test procedures for the KBM to closely control: 1) the initial horizontal position of the saw, 2) the contact angle, and 3) the approach velocity of the wood specimen. Initiation of 
a kickback during hand-held tests was achieved in the same manner so as to permit close control of the latter test parameters, which fundamentally influence the experimental initial and boundary conditions.

Furthermore, it was found from exploratory hand-held tests in which kickback was initiated by moving a saw guidebar toward a fixed wood specimen that the approach speed and initial saw position are more difficult to control if the saw guidebar is not supported. Alternatively, if a saw was supported on a level device which in turn is guided at a preset speed into a fixed wood specimen, then the time-dependent operator forces required to keep the moving saw in the proper alignment introduced other sources of test variability. Additional Test Procedures

In addition to the procedures associated with the kickback initiation, several other test procedures were required due to the use of volunteer chain saw operators. As has been indicated, the kickback initiation procedure used in the experimental program required that a test subject assume a passive mode. This mode simulated a bucking operation, with the guidebar partially supported as if a chain saw were cutting through a horizontally positioned limb. Based on data from the CPSC accident investigations, a guidebar support length of approximately $18 \mathrm{~cm}$ ( $7 \mathrm{in}$ ) was chosen. The test saw guidebar was held in a horizontal position by resting the guidebar safety shield on a wooden block. The thumb of the operator's left hand was hooked below the saw front handle, and the operator stood so that his/her body was to the side of the cutting plane (plane of chain rotation passing through the saw guidebar). For the additional safety of the operator, a wood barrier was placed in front of the operator to prevent excessive rotational saw motion. The primary consideration with regard to upper torso position was the comfort of the test subject. 
The rear handle of a chain saw typically has incorporarated into it the throttle control trigger. This trigger is usually a lever or switch activated by the operator's right index finger as his/her right hand grips the rear handle. It was necessary that all the test subjects keep a firm grip on the rear handle of the test saws. The requirement for squeezing the throttle control trigger to control the preset engine speed for a gasoline saw or activate an electric-powered saw tended to insure that the rear handle was properly gripped.

When the operator held the front handle of a test saw there were two specific requirements: 1) the fingers of the left hand were wrapped around the handle such that the handle diameter was kept in the webbing between the subject's thumb and index finger, and 2) the left hand was positioned on the handle such that it was approximately adjacent to the top end of the handle; i.e., the end of the handle closest to the cutting plane of the guidebar. The first of these requirements insured that the operator had the saw under control, whereas the second requirement was intended to minimize out-of-plane kickback motion of the test saw.

The test subjects were allowed to experience low energy kickbacks after the gripping and stance modes were explained and demonstrated by the principal investigator. For both the safety of the operators and the uniformity of the test results, the initial subject body position and method of gripping the test saws was maintained throughout the experimental program. Detailed discussions of the various human factors aspects of the program are given in Appendix B. 
Appendix B. Human Factors Recommendations and Rationale for Testing Chain Saw Kickback with Volunteer Operators.

\section{Introduction}

The Consumer Product Safety Commission (CPSC) funded the National Bureau of Standards (NBS) to develop and implement a test protocol and test procedures in order to obtain kickback data on chain saws operated by volunteer operators. NBS obtained the services of Bio Technology, Inc., to provide human factors recommendations for the test. This appendix presents Bio Technology's human factors recommendations and rationales for the kickback experimental program.

\section{$\underline{\text { Purpose }}$}

In support of chain saw standard development, NBS performed a study to measure the magnitude and relative difference in the kickback of different chain saws operated by individuals under conditions simulating consumer chain saw use. The objective of the study was not to measure human performance but rather to measure kickback performance of saw-person combinations.

\section{Representatives and Realism}

Insofar as possible the test protocol and procedures approximated the conditions of real-world saw use but in an environment that protected volunteer subjects from injury and that permited adequate experimental control to be exercised in taking kickback measurements. This required some compromise between safety and the generality of results to real-world saw use. 
Subject Characteristics

Ideally, subjects to be employed in the test should be statistically representative of the population of chain saw users. However, the user population characteristics were not known so the subpopulation of injured saw users as defined by the National Electronic Injury Surveillance System (NEISS) data were used to identify subject characteristics. Subject variables judged to be of importance in subject selection included: sex, age, weight, height, handedness (if this appears as a discriminating variable in the NEISS data) and chain saw use. Other subject variables, such as socio-economic status or educational achievement were not judged to be important variables in determining saw-user behavior.

\section{Sample Size and Selection}

Volunteers from NBS and the Consumer Product Safety Commission were used with full recognition that volunteers drawn from either organization may have special knowledge or attitudes on risk and safety which would limit the generality of findings to the injured population at large. The subject profiles are attached to the end of this appendix (table $B-2$ ).

\section{Subject Safety Vs. Realism}

To the maximum extent possible, the conditions (modified to insure subject safety) of saw use in the test were representative of the conditions of real-world use. All. subjects were required to wear hearing protectors to guard against the possibility of hearing loss, though such loss was not likely in the brief periods of exposure to the testing situation.

The test saws were held by subjects in a test arrangement that did not interfere with saw operation or attenuate saw kickback. Subjects were 
protected from facial injury by a transparent barrier, rather than a helmet, which did not restrict the size of the visual field or encumber subject movement. A shield covering the flat portion of the guidebar was employed to protect against injury to the limbs and torso without constraining the subject and without requiring an unnatural stance or grip of the saw during saw use. A floor covering was employed in order to reduce the possibility of slips and falls. Ambient lighting in the test environment was adequate for subjects to see and operate the saw and test samples.

The test environment was free from extraneous noise and distractions that would interfere with or stress subject performance or degrade oral communication between subjects and test personnel.

\section{Subject Treatment}

Prior to testing (at least one day in advance) all test subjects were given and required to read and understand saw safety guidelines provided by the CPSC. Subject release forms required subjects to attest to having read the CPSC safety guidelines prior to testing.

Prior to testing, each subject completed a questionnaire requesting information on the subject's sex, age, height, weight, and previous saw use experience. Other variables, such as corrected vision or occupation, were included in the questionnaire, but these variables are unlikely to be important sources of variance in subject performance.

All subjects were given the same oral instructions prior to testing. Standardization was insured by having the same test supervisor read the instructions to all the subjects. Instructions described what the subject was to do and how it was to be done. It was neither necessary nor desirable that the subject be informed of the purpose of the study since such knowledge might bias performance. 
All saws were tested by each subject. In order to account for the effects of subject learning (i.e., experience) on saw kickback, the order in which saws were presented was randomized across and within subjects as shown in table $\mathrm{B}-1$. Over half of the subjects tested were retested to determine if there were any differences between the first and second trial of saw use.

\section{Subject Tension/Relaxation}

Since the subject-saw combination is a mechanical linkage having unknown stiffness and damping characteristics, some estimate of the degree of tension or relaxation of the subject is desirable. Although myographic measures of muscle tension or other physiological measures could have been taken, their correlation with a subject's state of relaxation or tension is known not to be high. A somewhat better measure is self-perceived tension/relaxation. Each subject was asked to estimate his/her degree of relaxation or tension on a scale from 1 (very relaxed) to 5 (very tense) after each measurement trial. While this is a less than perfect tension measure, data from such ratings may partially account for between-subject differences in saw kickback. 8

\footnotetext{
${ }^{8}$ These ratings were recorded and evaluated by the CPSC for the kickback experimental program. The evaluation forms were analyzed by the CPSC Division of Human Factors.
} 
Table B-1. Chain saw hand-held test random match of subjects and saws.

\begin{tabular}{|c|c|c|c|c|c|}
\hline \multirow[b]{2}{*}{ Subject } & \multirow[b]{2}{*}{ Saw Order 1} & \multirow[b]{2}{*}{$\begin{array}{c}\text { Test } \\
\text { Series } \\
\end{array}$} & \multicolumn{3}{|c|}{ Saw Gl Trigger Match 2} \\
\hline & & & $\begin{array}{c}\text { Trigger } \\
\text { Used }\end{array}$ & $\begin{array}{c}\text { Times Rear } \\
\text { Trigger } \\
\text { was Used }\end{array}$ & $\begin{array}{c}\text { First } \\
\text { Trigger } \\
\text { Used }\end{array}$ \\
\hline 1 & $6,1,3,2,4,5,7$ & 1 & Rear & 5 & Rear \\
\hline 2 & $6,7,5,4,1,2,3$ & & Both & 3 & Rear \\
\hline 3 & $6,4,1,3,5,2,7$ & & Rear & 5 & Rear \\
\hline 4 & $6,4,5,2,7,3,1$ & & Front & 0 & Front \\
\hline 5 & $6,4,5,2,1,3,7$ & & Both & 3 & Rear \\
\hline 6 & $6,7,3,4,1,2,5$ & & Both & 2 & Front \\
\hline 7 & $6,5,7,1,2,4,3$ & & Both & 2 & Front \\
\hline 8 & $6,4,2,3,5,1,7$ & & Both & 2 & Rear \\
\hline 9 & $6,4,3,5,7,1,2$ & & Rear & 5 & Rear \\
\hline 10 & $6,3,1,5,7,2,4$ & & Front & 0 & Front \\
\hline 11 & $6,1,7,5,2,4,3$ & & Front & 0 & Front \\
\hline 10 & $6,2,5,3,1,7,4$ & 2 & Front & 0 & Front \\
\hline 3 & $6,3,1,4,2,5,7$ & & Front & 0 & Front \\
\hline 5 & $6,5,3,2,7,1,4$ & & Rear & 5 & Rear \\
\hline 11 & $6,4,1,5,7,3,2$ & & Both & 3 & Front \\
\hline 4 & $6,7,2,5,4,1,3$ & & Rear & 5 & Rear \\
\hline 9 & $6,4,1,7,5,2,3$ & & Front & 0 & Front \\
\hline 6 & $6,5,7,1,4,2,3$ & & Rear & 5 & Rear \\
\hline
\end{tabular}

${ }^{1}$ Random matches were provided by the Consumer Product Safety Commission. Saw E6 was presented first to each subject for training purposes, since it was a saw having relatively small kickback characteristics based on prior tests with the Kickback Test Machine.

${ }^{2}$ Saw Gl was the only test saw having two throttle triggers, both located on the rear handle. 


\section{Test Subject Evaluation}

The following evaluation sheet was prepared by the CPSC as another means of subject evaluation to supplement the measurements of saw kickback motion.

\section{TEST SUBJE:T EVALUAT:ON SHEET}

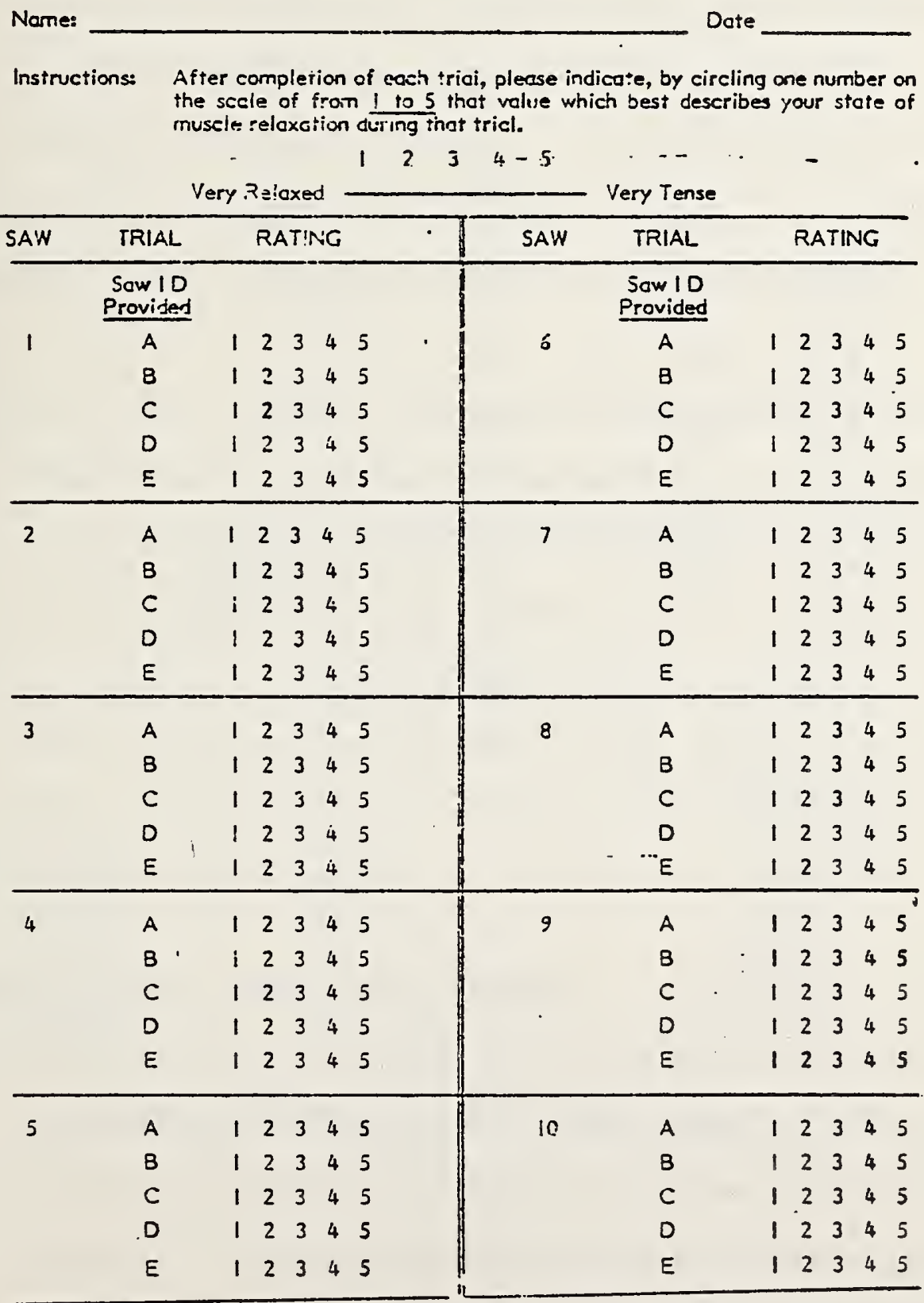

U.S. Consumer Product Sofety CommissionitHIEH 
Table B-2. Test subject profiles

\begin{tabular}{|c|c|c|c|c|c|c|}
\hline Subject & Sex & $\begin{array}{c}\text { Age } \\
\text { (years) }\end{array}$ & $\begin{array}{c}\text { Height } \\
\text { (in) }\end{array}$ & $\begin{array}{r}\text { Weight } \\
\text { (1bs) }\end{array}$ & Handed & $\begin{array}{c}\text { Chain Saw } \\
\text { Use }\end{array}$ \\
\hline $\mathrm{CR}$ & M & 55 & 65 & 154 & $\mathrm{R}$ & Yes \\
\hline CHD & M & 40 & 71 & 176 & $\mathrm{R}$ & Yes \\
\hline NB & M & 44 & 59 & 160 & $\mathrm{R}$ & Yes \\
\hline $\mathrm{CN}$ & F & 54 & 63 & 128 & $\mathrm{R}$ & Yes \\
\hline $\mathrm{CJ}$ & M & 43 & 65 & 158 & $\mathrm{R}$ & Yes \\
\hline$C D$ & M & 33 & 69 & 184 & $\mathrm{R}$ & Yes \\
\hline CMJ & M & 31 & 76 & 197 & $\mathrm{R}$ & Yes \\
\hline CDS & $\mathrm{F}$ & 25 & 65 & 112 & $\mathrm{R}$ & No \\
\hline $\mathrm{CA}$ & $\mathrm{M}$ & 43 & 67 & 198 & $\mathrm{R}$ & Yes \\
\hline $\mathrm{CK}$ & M & 33 & 67 & 174 & L & No \\
\hline CS & M & 42 & 75 & 286 & $\mathrm{R}$ & Yes \\
\hline
\end{tabular}


Appendix C. Computer Analysis of Recorded Data.

A high-speed computer was utilized to perform necessary corrections and transformations of the digitized saw displacement data recorded by the optoelectronic measurement system. This analysis included corrections for lens curvature of the recording camera and for the desired diode positions to facilitate interpretation of the saw motion relative to the body of a chain saw operator. Transformations of the data to a coordinate system at the saw center of gravity when the kickback was initiated (time $=0$ ), and conversion of the displacements from the measurement system units to inches were also performed.

Furthermore, it was required that the saw rotational motion during a kickback be defined relative to three saw references: 1) the moving center of gravity of the saw, 2) a fixed reference at the rearmost position of the saw as the kickback was initiated (CPSC definition of the derived rotation angle), and 3 ) a fixed reference at the rear handle throttle trigger at the kickback initiation (CSMA definition of the derived rotation angle). The equations for these corrections and transformations of the recorded data are given in the following sections of this appendix.

\section{Correction for Recording Camera Lens Curvature}

A program was written for calculating the change in the diode coordinates, due to distortion in Selspot camera system, using a look-up table. The program corrects for the discrepancies between the known calibration points in the object space and the optically produced position of these points.

A grid of 1024 by 1024 coordinate components used by the Selspot electronics (a direct result of a 10-bit word address) is divided up into $289 \mathrm{x}-$ components and $289 \mathrm{y}$-components which are each represented by a 17 by 17 
matrix or look-up table. For the program printed at the end of this appendix, the $\mathrm{x}$ and $\mathrm{y}$ look-up tables are given in tenths of millimeters. Conversion from millimeters to inches is performed after an interpolation process is completed.

Under controlled laboratory conditions, the true grid (1600 mm by 1600 $\mathrm{mm}$ ) was measured by the Selspot System, as shown in figure C-1. Subsequently, corrected look-up tables were generated to account for the change in coordinates due to lens distortions. By incorporating these corrected look-up tables, a simple interpolation routine was then used to find the corrected coordinates from those recorded by the Selspot System during the kickback tests. One critical factor that had to be taken into account in the above analysis was the camera-to-object distance. This factor was entered as a constant related to the camera-to-grid distance used in the initial calibration of the Selspot System.

Conversion of Diode Positions and Computation of CPSC Kickback Angles

Throughout the experimental program, the positions of the saw tip, center of gravity, and rear handle were defined by the coordinates (X3,Y3), (X4,Y4), and $(X 5, Y 5)$, respectively. In general, the diodes were placed adjacent to, but not exactly at the desired saw positions. The parameters used to relate the test coordinates and these desired positions for the diodes at the saw tip, center of gravity, and rear handle were $(A 1, A 2),(C 1, C 2)$, and $(R 1, R 2)$, respectively, when the saw was in its original position at the inception of kickback, i.e., at time $t=0$. Table $\mathrm{C}-1$ summarizes the saw parameters required for these computations. At the time chosen as $t=0$, the following constants define the saw initial position: 


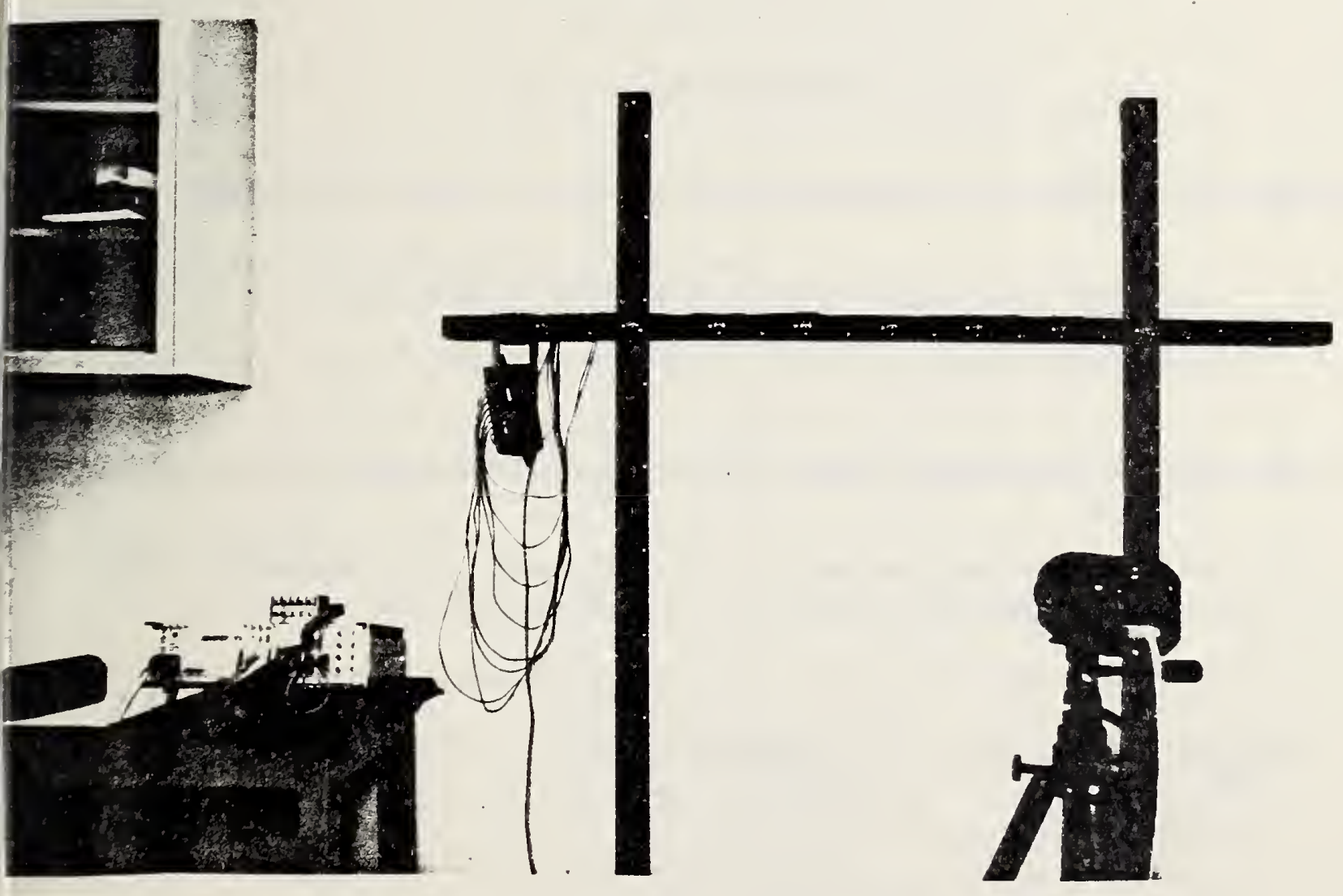

Figure C.1. Arrangement of Optoelectronic Camera and Calibration Grid (instrumented bar moved to various elevations) 


$$
\begin{aligned}
& \mathrm{VO}=\mathrm{Y3} \\
& \mathrm{HO}=\mathrm{X} 3 \\
& \mathrm{YO}=\mathrm{Y} 4 \\
& \mathrm{XO}=\mathrm{X} 4
\end{aligned}
$$

At the inception of kickback $(t=0)$, let

$$
\begin{aligned}
& \mathrm{S} 1=\mathrm{X} 5+\mathrm{R} 1 \\
& \mathrm{~S} 2=\mathrm{Y} 5+\mathrm{R} 2 \\
& \mathrm{Q} 1=\mathrm{X} 0+\mathrm{C} 1 \\
& \mathrm{Q} 2=\mathrm{Y} 0+\mathrm{C} 2
\end{aligned}
$$

\begin{tabular}{|c|c|c|c|c|c|c|c|}
\hline Test & Tip & Corre & tion (in) & C.G. Corr & tion (in) & Handle cor & tion (in) \\
\hline Saw & & $\mathrm{Al}$ & $\mathrm{A} 2$ & $\mathrm{Cl}$ & $\mathrm{C} 2$ & $\mathrm{R} 1$ & $\mathrm{R} 2$ \\
\hline G1 & & 1.00 & -0.44 & 0 & 0 & -2.12 & +0.69 \\
\hline G2 & & 1.31 & +1.06 & +0.06 & 0 & -1.56 & -1.31 \\
\hline G3 & & 1.31 & +0.88 & -0.38 & +0.88 & -2.62 & +0.50 \\
\hline G4 & & 0.75 & +1.12 & 0.0 & -0.75 & -2.56 & +1.62 \\
\hline G5 & & 1.69 & +0.34 & +0.16 & +0.06 & +0.12 & -0.03 \\
\hline E6 & & 1.25 & 0 & +0.62 & +0.50 & -2.44 & -0.12 \\
\hline E7 & & 1.75 & +0.81 & +0.19 & +0.19 & -0.50 & +0.19 \\
\hline
\end{tabular}

The rotation of the saw about its center of gravity is then defined as

$$
A=\tan ^{-1}[(Y 3-Y 4) /(X 3-X 4)]-\tan ^{-1}[(V 0-Y 0) /(H 0-X 0)]
$$

where $A$ is an angle in degrees for all times during the kickback event.

Table C-1. Saw paremeters used to correct diode test coordinates to desired positions.

\section{Rear}


The corrected positions for the diode positions at the saw tip, center of gravity, and rear handle are defined as (T1, T2), (G1, G2), and (H1, H2), respectively, and are computed as follows:

$$
\begin{aligned}
& \mathrm{T} 1=\mathrm{X} 3+\mathrm{A} 1 \cos A-A 2 \operatorname{in} A \\
& \mathrm{~T} 2=\mathrm{Y} 3+\mathrm{A} 1 \sin A+\mathrm{A} 2 \cos A \\
& \mathrm{G} 1=\mathrm{X} 4+\mathrm{C} 1 \cos A-C 2 \sin A \\
& \mathrm{G} 2=\mathrm{Y} 4+\mathrm{C} 1 \sin A+C 2 \cos A \\
& \mathrm{H} 1=\mathrm{X} 5+\mathrm{R} 1 \cos A-R 2 \sin A \\
& \mathrm{H} 2=\mathrm{Y} 5+\mathrm{R} 1 \sin A+R 2 \cos A
\end{aligned}
$$

The derived angle of rotation (DAR) relative to a fixed position at the rear of the saw is computed as follows:

$$
D=\tan ^{-1}[(\mathrm{~T} 2-\mathrm{S} 2) /(\mathrm{T} 1-\mathrm{S} 1)]-\tan ^{-1}[(\mathrm{~V} 0+\mathrm{A} 2-\mathrm{S} 2) /(\mathrm{H} 0+\mathrm{A} 1-\mathrm{S} 1)]
$$

where $D$ is the angle in degrees for all times during the kickback (CPSC definition of DAR).

To convert the displacement data to the coordinate system whose origin is at the saw center of gravity as it moves, the following transformations are used:

$$
\begin{aligned}
& \mathrm{T} 1=\mathrm{T} 1-\mathrm{Q} 1 \\
& \mathrm{~T} 2=\mathrm{T} 2-\mathrm{Q} 2 \\
& \mathrm{G} 1=\mathrm{G} 1-\mathrm{Q} 1 \\
& \mathrm{G} 2=\mathrm{G} 2-\mathrm{Q} 2 \\
& \mathrm{H} 1=\mathrm{H} 1-\mathrm{Q} 1 \\
& \mathrm{H} 2=\mathrm{H} 2-\mathrm{Q} 2
\end{aligned}
$$


where $(\mathrm{T} 1, \mathrm{~T} 2),(\mathrm{G} 1, \mathrm{G} 2)$, and $(\mathrm{H} 1, \mathrm{H} 2)$ define the $(\mathrm{X}, \mathrm{Y})$ coordinates at the saw tip, center of gravity, and rear handle, respectively, for all times during the kickback.

\section{Computation of CSMA Derived Angle of Rotation}

In order to compute the derived angle of rotation in terms of the CSMA reference system, it is necessary to use additional saw parameters. These parameters define the $(X, Y)$ coordinates of the rear handle throttle trigger at the kickback initiation and locate the guidebar tip coordinates somewhat differently than for the CPSC reference system. The parameters (L3, L4) and (A3,A4) define the trigger and tip coordinates, respectively, and are summarized for the various test saws in table $\mathrm{C}-2$.

Table C-2. Saw parameters used to compute CSMA derived angle of rotation.

\section{Test Saw}

G1

G2

G3

G4

G5

E6

E7

3

4

\begin{tabular}{llll}
\multicolumn{4}{c}{ Saw Dimensions (in) } \\
\hline L3 & $\mathrm{L} 4$ & $\mathrm{A3}$ & $\mathrm{A} 4$ \\
\hline
\end{tabular}

$$
+6.06^{1}
$$$$
+2.441
$$

$-1.12$

$-0.93$

$+4.06$

$+3.00$

$-1.06$

$-0.93$

$$
+3.75
$$

$+2.31$

$-0.87$

$-0.94$

$$
+9.00
$$

$+1.25$

$-1.13$

$-1.12$

$+8.69+0.62$

$-1.13$

$-1.07$

$$
0^{2}
$$

0

$$
0
$$

0

$+6.06+0.94$

$-0.75$

$-0.69$

1 Dimensions for L3 and L4 were based on measurements at the rear trigger location for test saw Gl.

${ }^{2}$ Saw dimensions not measured for test saw E6. Values of zero were used to implement running of the computer program. 
Using the definitions for $\mathrm{T} 1, \mathrm{~T} 2, \mathrm{~A}, \mathrm{Q} 1$, and $\mathrm{Q} 2$, as defined in eqs. (C.7) through (C.11), the following expressions are computed at each time:

$$
\begin{aligned}
& \mathrm{T} 3=\mathrm{T} 1+\mathrm{A} 3 \cos \mathrm{A}-\mathrm{A} 4 \sin \mathrm{A}-\mathrm{Q} 1 \\
& \mathrm{~T} 4=\mathrm{T} 2+\mathrm{A} 3 \sin \mathrm{A}+\mathrm{A} 4 \cos \mathrm{A}-\mathrm{Q} 2
\end{aligned}
$$

The CSMA derived angle of rotation (DAR) relative to a fixed position at the throttle trigger is computed as follows:

$$
B=\tan ^{-1}[(T 4-L 4) /(T 3-L 3)]
$$

where $B$ is the DAR in degrees for all times during the kickback.

\section{Computer Analysis}

Equations for the corrections and the transformations which have been discussed were programmed for a mini-computer to analyze the recorded kickback displacement data; the software for this analysis is given at the end of the appendix. Examples of the corrected values for the CPSC and CSMA derived angles of rotation for Test Subjects $\mathrm{CDS}$ and $\mathrm{NB}$ are given in tables $\mathrm{C}-3$ and C-4, respectively.

Corrections due to distortion in the recording camera system were found to change the computed angles of rotation by approximately one degree or less, based on comparison of corrected and uncorrected displacement data. Corrections due to the diode positions generally modified the computed angles of rotation by two degrees or less.

In order to facilitate the interpretation of the saw rotational motion during the kickback tests, the maximum rotation angles about the saw center of gravity were determined for Test Subjects CDS and NB and are presented in tables $\mathrm{C}-5$ and $\mathrm{C}-6$, respectively. The time intervals from the first contact of the saw and wood specimen to the point of maximum rotation about the moving 
saw center of gravity are also shown; these values were less than or equal to the times required for the saws to reach the maximum values for the derived angles of rotation shown in tables $\mathrm{C}-5$ and $\mathrm{C}-6$. A sample of the computer analysis is given following table $c-6$. 
Table C-3. Corrected values of kickback derived angles of rotation (DAR) for subject CDS.

Test Test (DAR) CPSC for Replicate Tests (deg) Average Std. Coef. of Ser. Saw [(DAR)CSMA for Replicate Tests (deg)] DAR,deg Dev. Variation

\begin{tabular}{|c|c|c|c|c|c|c|c|c|}
\hline GI. & $\begin{array}{c}26.6 \\
{[22.3]}\end{array}$ & $\begin{array}{c}28.4 \\
{[24.7]}\end{array}$ & $\begin{array}{c}31.0 \\
{[27.6]}\end{array}$ & $\begin{array}{l}1 \\
1\end{array}$ & $\begin{array}{c}26.7 \\
{[22.5]}\end{array}$ & 28.2 & 2.06 & 0.07 \\
\hline $\mathrm{G} 2$ & $\begin{array}{c}40.8 \\
{[42.4]}\end{array}$ & $\begin{array}{c}23.8 \\
{[20.2]}\end{array}$ & $\begin{array}{c}30.4 \\
{[28.3]}\end{array}$ & $\begin{array}{c}32.8 \\
{[32.3]}\end{array}$ & $\begin{array}{c}28.5 \\
{[26.9]}\end{array}$ & 31.3 & 6.27 & 0.20 \\
\hline G3 & $\begin{array}{c}22.1 \\
{[18.9]}\end{array}$ & $\begin{array}{c}18.5 \\
{[14.6]}\end{array}$ & $\begin{array}{c}24.5 \\
{[26.3]}\end{array}$ & $\begin{array}{c}31.2 \\
{[30.3]}\end{array}$ & $\begin{array}{c}33.6 \\
{[33.8]}\end{array}$ & 26.0 & 6.29 & 0.24 \\
\hline G4 & $\begin{array}{r}54.4^{2} \\
{[54.5]}\end{array}$ & $\begin{array}{c}51.1 \\
{[51.7]}\end{array}$ & $\begin{array}{c}37.7 \\
{[38.4]}\end{array}$ & $\begin{array}{c}38.7 \\
{[39.1]}\end{array}$ & $\begin{array}{c}53.5 \\
{[54.8]}\end{array}$ & 47.1 & 8.20 & 0.17 \\
\hline G5 & $\begin{array}{c}49.9 \\
{[51.2]}\end{array}$ & $\begin{array}{c}32.9 \\
{[33.6]}\end{array}$ & $\begin{array}{r}52.9^{2} \\
{[53.8]}\end{array}$ & $\begin{array}{l}51.1^{2} \\
{[52.4]}\end{array}$ & $\begin{array}{c}48.9 \\
{[49.0]}\end{array}$ & 47.1 & 8.10 & 0.17 \\
\hline E7 & $\begin{array}{c}15.7 \\
{[14.3]}\end{array}$ & $\begin{array}{c}15.2 \\
{[13.6]}\end{array}$ & $\begin{array}{c}19.9 \\
{[18.7]}\end{array}$ & $\begin{array}{c}14.0 \\
{[12.4]}\end{array}$ & $\begin{array}{c}32.9 \\
{[34.5]}\end{array}$ & 19.5 & 7.79 & 0.40 \\
\hline GI & $\begin{array}{l}1 \\
1\end{array}$ & $\begin{array}{c}27.7 \\
{[21.9]}\end{array}$ & {$\left[\begin{array}{c}16.6 \\
{[9.2]}\end{array}\right.$} & $\begin{array}{c}26.2 \\
{[20.3]}\end{array}$ & $\begin{array}{c}19.3 \\
{[12.8]}\end{array}$ & 22.4 & 5.35 & 0.24 \\
\hline G2 & $\begin{array}{c}34.5 \\
{[33.5]}\end{array}$ & $\begin{array}{c}33.2 \\
{[31.1]}\end{array}$ & $\begin{array}{l}1 \\
1\end{array}$ & $\begin{array}{c}26.0 \\
{[19.3]}\end{array}$ & $\begin{array}{c}36.4 \\
{[34.7]}\end{array}$ & 32.5 & 4.54 & 0.14 \\
\hline G3 & $\begin{array}{c}33.3 \\
{[32.4]}\end{array}$ & $\begin{array}{c}42.9 \\
{[46.9]}\end{array}$ & $\begin{array}{c}27.9 \\
{[26.7]}\end{array}$ & $\begin{array}{c}28.6 \\
{[27.3]}\end{array}$ & $\begin{array}{c}27.5 \\
{[26.1]}\end{array}$ & 32.0 & 6.50 & 0.20 \\
\hline G4 & $\begin{array}{r}53.1^{2} \\
{[53.7]}\end{array}$ & $\begin{array}{r}54.6^{2} \\
{[54.5]}\end{array}$ & $\begin{array}{c}31.2 \\
{[30.3]}\end{array}$ & $\begin{array}{c}36.8 \\
{[36.0]}\end{array}$ & $\begin{array}{c}44.8 \\
{[44.2]}\end{array}$ & 44.1 & 10.14 & 0.23 \\
\hline G5 & $\begin{array}{r}50.3^{2} \\
{[50.7]}\end{array}$ & $\begin{array}{r}50.5^{2} \\
{[52.1]}\end{array}$ & $\begin{array}{r}53.0^{2} \\
{[53.9]}\end{array}$ & $\begin{array}{r}53.5^{2} \\
{[54.4]}\end{array}$ & $\begin{array}{c}47.4 \\
{[47.9]}\end{array}$ & 50.9 & 2.45 & 0.05 \\
\hline E7 & $\begin{array}{c}12.6 \\
{[10.2]}\end{array}$ & $\begin{array}{c}21.8 \\
{[21.7]}\end{array}$ & $\begin{array}{c}22.2 \\
{[21.2]}\end{array}$ & 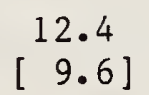 & $\begin{array}{c}18.0 \\
{[15.8]}\end{array}$ & 17.4 & 4.76 & 0.27 \\
\hline
\end{tabular}

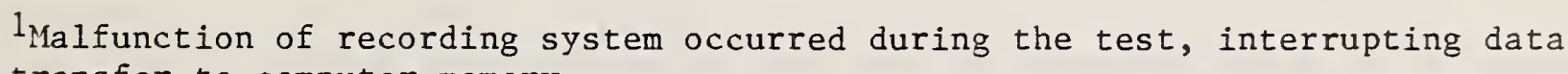
transfer to computer memory.

${ }^{2}$ Saw struck safety bar.

NOTE: for test saw GI, (DAR) CSMA was based on the rear trigger location. 
Table C-4. Corrected values of kickback derived angles of rotation (DAR) for subject NB.

Test Test (DAR)CPSC for Replicate Tests (deg) Average Std. Coef. of Ser. Saw [(DAR) CSMA for Replicate Tests (deg)] DAR,deg Dev. Variation

\begin{tabular}{|c|c|c|c|c|c|c|c|c|c|}
\hline 1 & G1 & {$\left[\begin{array}{c}13.1 \\
{[8.2]}\end{array}\right.$} & $\begin{array}{c}15.5 \\
{\left[\begin{array}{c}8.4 \\
0\end{array}\right]}\end{array}$ & $\begin{array}{c}11.5 \\
{[9.0]}\end{array}$ & $\begin{array}{l}9.5 \\
{[8.6]}\end{array}$ & $\begin{array}{c}11.3 \\
{[9.1]}\end{array}$ & 12.2 & 2.25 & 0.18 \\
\hline & G2 & $\begin{array}{c}12.8 \\
{[6.6]}\end{array}$ & $\begin{array}{c}17.2 \\
{[12 \cdot 2]}\end{array}$ & $\begin{array}{c}15.5 \\
{[9.5]}\end{array}$ & $\begin{array}{c}16.6 \\
{[10.4]}\end{array}$ & {$\left[\begin{array}{c}15.4 \\
{[8.9]}\end{array}\right.$} & 15.5 & 1.69 & 0.11 \\
\hline & G3 & $\begin{array}{c}11.4 \\
{[4.9]}\end{array}$ & $\begin{array}{l}9.1 \\
{[9.5]}\end{array}$ & $\begin{array}{c}12.1 \\
{[5.9]}\end{array}$ & $\begin{array}{c}15.3 \\
{[10.3]}\end{array}$ & 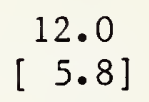 & 12.0 & 2.22 & 0.18 \\
\hline & G4 & $\begin{array}{r}41.0^{2} \\
{[40.6]}\end{array}$ & $\begin{array}{c}39.3 \\
{[39.1]}\end{array}$ & $\begin{array}{c}46.0 \\
{[45.4]}\end{array}$ & $\begin{array}{c}43.1 \\
{[42.7]}\end{array}$ & $\begin{array}{c}32.7 \\
{[31.7]}\end{array}$ & 40.4 & 4.99 & 0.12 \\
\hline • & G5 & $\begin{array}{c}22.4 \\
{[21.6]}\end{array}$ & $\begin{array}{r}51.92 \\
{[51.4]}\end{array}$ & $\begin{array}{c}43.2 \\
{[42.3]}\end{array}$ & $\begin{array}{c}36.0 \\
{[35.2]}\end{array}$ & $\begin{array}{c}22.7 \\
{[21.6]}\end{array}$ & 35.2 & 12.88 & 0.36 \\
\hline & E7 & $\begin{array}{c}19.7 \\
{[18.1]}\end{array}$ & $\begin{array}{c}33.4 \\
{[34.8]}\end{array}$ & $\begin{array}{c}25.4 \\
{[24.8]}\end{array}$ & $\begin{array}{l}9.8 \\
{\left[\begin{array}{l}5.8\end{array}\right]}\end{array}$ & $\begin{array}{c}11.4 \\
{[8.4]}\end{array}$ & 19.9 & 9.83 & 0.49 \\
\hline 2 & Gl & $\begin{array}{r}15.5 \\
5.9\end{array}$ & $\begin{array}{c}20.9 \\
{[13.8]}\end{array}$ & $\begin{array}{c}12.9 \\
{\left[\begin{array}{c}5.1\end{array}\right]}\end{array}$ & $\begin{array}{l}1 \\
1\end{array}$ & $\begin{array}{c}15.9 \\
{\left[\begin{array}{c}7.6]\end{array}\right]}\end{array}$ & $16 \cdot 3$ & 3.34 & 0.20 \\
\hline & G2 & $\begin{array}{c}26.4 \\
{[19.9]}\end{array}$ & $\begin{array}{c}16.6 \\
{[10.9]}\end{array}$ & $\begin{array}{c}32.0 \\
{[28.5]}\end{array}$ & $\begin{array}{c}18.9 \\
{[11.6]}\end{array}$ & $\begin{array}{c}17.0 \\
{[9.2]}\end{array}$ & 22.2 & 6.76 & 0.30 \\
\hline & G3 & $\begin{array}{l}22.2 \\
{[18.5]}\end{array}$ & $\begin{array}{c}24.7 \\
{[22.6]}\end{array}$ & $\begin{array}{c}17.5 \\
{[12.2]}\end{array}$ & $\begin{array}{l}18.4 \\
{[13.5]}\end{array}$ & $\begin{array}{c}13.3 \\
{[7.2]}\end{array}$ & 19.2 & $4 \cdot 40$ & 0.23 \\
\hline & G4 & $\begin{array}{c}50.3 \\
{[49.8]}\end{array}$ & $\begin{array}{c}47.6 \\
{[46.8]}\end{array}$ & $\begin{array}{c}35.6 \\
{[34.3]}\end{array}$ & $\begin{array}{c}43.3 \\
{[42.4]}\end{array}$ & $\begin{array}{c}36.6 \\
{[35.3]}\end{array}$ & 42.7 & 6.51 & 0.15 \\
\hline & G5 & $\begin{array}{l}52.8 \\
{[53.9]}\end{array}$ & $\begin{array}{c}58.8 \\
{[60.5]}\end{array}$ & $\begin{array}{c}33.2 \\
{[33.0]}\end{array}$ & $\begin{array}{c}45.2 \\
{[46.2]}\end{array}$ & $\begin{array}{c}28.9 \\
{[28.9]}\end{array}$ & 43.8 & 12.67 & 0.29 \\
\hline & E7 & $\begin{array}{l}7.0 \\
{[4.2]}\end{array}$ & $\begin{array}{l}9.1 \\
{[6.8]}\end{array}$ & $\begin{array}{c}10.3 \\
{[8.2]}\end{array}$ & $\begin{array}{c}14.8 \\
{[12.7]}\end{array}$ & {$\left[\begin{array}{c}10.4 \\
{[8.2]}\end{array}\right.$} & 10.3 & 2.85 & 0.28 \\
\hline
\end{tabular}

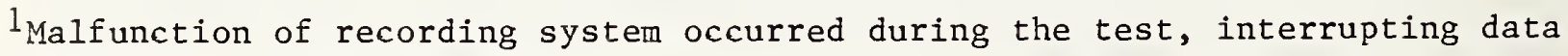
transfer to computer memory.

${ }^{2}$ Saw struck safety bar.

NOTE: for test saw Gl, (DAR)CSMA was based on the rear trigger location. 
Table C-5. Maximum angles of kickback rotation about saw center of gravity for subject CDS.

\begin{tabular}{|c|c|c|c|c|c|c|c|}
\hline $\begin{array}{c}\text { Test } \\
\text { Series } \\
\end{array}$ & $\begin{array}{l}\text { Test } \\
\text { Saw }\end{array}$ & \multicolumn{2}{|c|}{$\begin{array}{l}\text { Maximum Rotati } \\
\text { (Duration from }\end{array}$} & $\begin{array}{l}\text { n about } \\
\text { Saw-Wood }\end{array}$ & $\begin{array}{l}\text { Saw C.G., } \\
\text { Contact, }\end{array}$ & $\begin{array}{l}\text { deg } \\
\text { sec) }\end{array}$ & $\begin{array}{c}\text { Average } \\
\text { Duration, } \\
\text { sec. }\end{array}$ \\
\hline \multirow[t]{6}{*}{1} & Gl & $\begin{array}{l}23.2 \\
(0.413)\end{array}$ & $\begin{array}{l}25.4 \\
(0.446)\end{array}$ & $\begin{array}{l}29.2 \\
(0.401)\end{array}$ & $\begin{array}{l}1 \\
1\end{array}$ & $\begin{array}{l}27.8 \\
(0.433)\end{array}$ & 0.423 \\
\hline & G2 & $\begin{array}{l}38.3 \\
(0.099)\end{array}$ & $\begin{array}{l}26.7 \\
(0.086)\end{array}$ & $\begin{array}{l}33.0 \\
(0.093)\end{array}$ & $\begin{array}{l}37.3 \\
(0.086)\end{array}$ & $\begin{array}{l}32.7 \\
(0.086)\end{array}$ & 0.090 \\
\hline & G3 & $\begin{array}{l}26.4 \\
(0.080)\end{array}$ & $\begin{array}{l}24.3 \\
(0.080)\end{array}$ & $\begin{array}{l}29.4 \\
(0.093)\end{array}$ & $\begin{array}{l}28.0 \\
(0.086)\end{array}$ & $\begin{array}{l}36.8 \\
(0.093)\end{array}$ & 0.086 \\
\hline & G4 & $\begin{array}{l}47.0 \\
(0.231)\end{array}$ & $\begin{array}{l}44.2 \\
(0.196)\end{array}$ & $\begin{array}{l}38.0 \\
(0.109)\end{array}$ & $\begin{array}{l}39.5 \\
(0.112)\end{array}$ & $\begin{array}{l}48.8 \\
(0.218)\end{array}$ & 0.173 \\
\hline & G5 & $\begin{array}{l}50.3 \\
(0.099)\end{array}$ & $\begin{array}{l}36.2 \\
(0.096)\end{array}$ & $\begin{array}{l}59.9 \\
(0.090)\end{array}$ & $\begin{array}{l}57.6 \\
(0.099)\end{array}$ & $\begin{array}{l}46.9 \\
(0.102)\end{array}$ & 0.097 \\
\hline & E7 & $\begin{array}{l}18.4 \\
(0.064)\end{array}$ & $\begin{array}{l}17.5 \\
(0.067)\end{array}$ & $\begin{array}{l}21.9 \\
(0.093)\end{array}$ & $\begin{array}{l}19.3 \\
(0.080)\end{array}$ & $\begin{array}{l}29.9 \\
(0.096)\end{array}$ & 0.080 \\
\hline \multirow[t]{6}{*}{2} & G1 & $\begin{array}{l}1 \\
1\end{array}$ & $\begin{array}{l}22.0 \\
(0.423)\end{array}$ & $\begin{array}{l}20.3 \\
(0.118)\end{array}$ & $\begin{array}{l}26.1 \\
(0.125)\end{array}$ & $\begin{array}{l}20.6 \\
(0.458)\end{array}$ & 0.281 \\
\hline & G2 & $\begin{array}{l}35.6 \\
(0.096)\end{array}$ & $\begin{array}{l}33.3 \\
(0.096)\end{array}$ & $\begin{array}{l}1 \\
1\end{array}$ & $\begin{array}{l}22.9 \\
(0.071)\end{array}$ & $\begin{array}{l}28.2 \\
(0.080)\end{array}$ & 0.086 \\
\hline & G3 & $\begin{array}{l}30.4 \\
(0.093)\end{array}$ & $\begin{array}{l}38.7 \\
(0.115)\end{array}$ & $\begin{array}{l}32.8 \\
(0.096)\end{array}$ & $\begin{array}{l}32.1 \\
(0.093)\end{array}$ & $\begin{array}{l}27.2 \\
(0.096)\end{array}$ & 0.099 \\
\hline & G4 & $\begin{array}{l}49.8 \\
(0.147)\end{array}$ & $\begin{array}{l}52.8 \\
(0.125)\end{array}$ & $\begin{array}{l}31.2 \\
(0.093)\end{array}$ & $\begin{array}{l}35.5 \\
(0.109)\end{array}$ & $\begin{array}{l}38.6 \\
(0.471)\end{array}$ & 0.189 \\
\hline & G5 & $\begin{array}{l}52.1 \\
(0.112)\end{array}$ & $\begin{array}{l}53.4 \\
(0.106)\end{array}$ & $\begin{array}{l}60.4 \\
(0.093)\end{array}$ & $\begin{array}{l}59.7 \\
(0.090)\end{array}$ & $\begin{array}{l}43.1 \\
(0.106)\end{array}$ & 0.101 \\
\hline & E7 & $\begin{array}{l}14.7 \\
(0.064)\end{array}$ & $\begin{array}{l}26.0 \\
(0.096)\end{array}$ & $\begin{array}{l}25.6 \\
(0.090)\end{array}$ & $\begin{array}{l}15.5 \\
(0.077)\end{array}$ & $\begin{array}{l}20.9 \\
(0.077)\end{array}$ & 0.081 \\
\hline
\end{tabular}

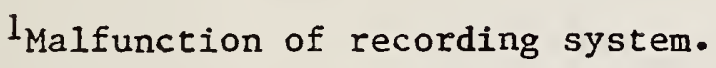


Table C-6. Maximum angles of kickback rotation about saw center of gravity for subject NB.

\begin{tabular}{|c|c|c|c|c|c|c|c|}
\hline $\begin{array}{c}\text { Test } \\
\text { Series } \\
\end{array}$ & $\begin{array}{l}\text { Test } \\
\text { Saw } \\
\end{array}$ & \multicolumn{2}{|c|}{$\begin{array}{l}\text { Maximum Rotatio } \\
\text { (Duration from }\end{array}$} & $\begin{array}{l}\text { on about } \\
\text { Saw-Wood }\end{array}$ & $\begin{array}{l}\text { Saw C.G., } \\
\text { Contact, }\end{array}$ & $\begin{array}{l}\text { deg } \\
\text { sec) }\end{array}$ & $\begin{array}{c}\text { Average } \\
\text { Duration, } \\
\text { sec } \\
\end{array}$ \\
\hline \multirow[t]{6}{*}{1} & G1 & $\begin{array}{l}13.3 \\
(0.676)\end{array}$ & $\begin{array}{l}13.9 \\
(0.609)\end{array}$ & $\begin{array}{l}11.1 \\
(0.452)\end{array}$ & $\begin{array}{l}8.0 \\
(0.401)\end{array}$ & $\begin{array}{l}10.7 \\
(0.494)\end{array}$ & 0.526 \\
\hline & G2 & $\begin{array}{l}14.4 \\
(0.054)\end{array}$ & $\begin{array}{l}19.2 \\
(0.067)\end{array}$ & $\begin{array}{l}17.4 \\
(0.051)\end{array}$ & $\begin{array}{l}17.7 \\
(0.067)\end{array}$ & $\begin{array}{l}16.5 \\
(0.054)\end{array}$ & 0.059 \\
\hline & G3 & $\begin{array}{l}14.1 \\
(0.061)\end{array}$ & $\begin{array}{l}12.9 \\
(0.064)\end{array}$ & $\begin{array}{l}15.0 \\
(0.054)\end{array}$ & $\begin{array}{l}19.5 \\
(0.067)\end{array}$ & $\begin{array}{l}10.7 \\
(0.056)\end{array}$ & 0.062 \\
\hline & G4 & $\begin{array}{l}37.8 \\
(0.154)\end{array}$ & $\begin{array}{l}39.1 \\
(0.115)\end{array}$ & $\begin{array}{l}41.4 \\
(0.160)\end{array}$ & $\begin{array}{l}40.2 \\
(0.151)\end{array}$ & $\begin{array}{l}33.3 \\
(0.099)\end{array}$ & 0.136 \\
\hline & G5 & $\begin{array}{l}24.7 \\
(0.083)\end{array}$ & $\begin{array}{l}47.7 \\
(0.118)\end{array}$ & $\begin{array}{l}39.0 \\
(0.090)\end{array}$ & $\begin{array}{l}36.3 \\
(0.090)\end{array}$ & $\begin{array}{l}25.2 \\
(0.083)\end{array}$ & 0.093 \\
\hline & E7 & $\begin{array}{l}16.9 \\
(0.497)\end{array}$ & $\begin{array}{l}25.7 \\
(0.510)\end{array}$ & $\begin{array}{l}22.4 \\
(0.436)\end{array}$ & $\begin{array}{l}11.9 \\
(0.048)\end{array}$ & $\begin{array}{l}14.0 \\
(0.054)\end{array}$ & 0.309 \\
\hline \multirow[t]{6}{*}{2} & G1 & $\begin{array}{l}11.5 \\
(0.474)\end{array}$ & $\begin{array}{l}16.8 \\
(0.381)\end{array}$ & $\begin{array}{l}11.2 \\
(0.064)\end{array}$ & $\begin{array}{l}1 \\
1\end{array}$ & $\begin{array}{l}12.4 \\
(0.401)\end{array}$ & 0.330 \\
\hline & G2 & $\begin{array}{l}18.8 \\
(0.070)\end{array}$ & $\begin{array}{l}19.0 \\
(0.074)\end{array}$ & $\begin{array}{l}19.4 \\
(0.086)\end{array}$ & $\begin{array}{l}16.6 \\
(0.080)\end{array}$ & $\begin{array}{l}12.9 \\
(0.074)\end{array}$ & 0.077 \\
\hline & G3 & $\begin{array}{l}25.4 \\
(0.077)\end{array}$ & $\begin{array}{l}30.1 \\
(0.090)\end{array}$ & $\begin{array}{l}19.8 \\
(0.077)\end{array}$ & $\begin{array}{l}20.6 \\
(0.083)\end{array}$ & $\begin{array}{l}15.6 \\
(0.064)\end{array}$ & 0.078 \\
\hline & G4 & $\begin{array}{l}44.5 \\
(0.189)\end{array}$ & $\begin{array}{l}38.9 \\
(0.336)\end{array}$ & $\begin{array}{l}31.2 \\
(0.138)\end{array}$ & $\begin{array}{l}38.0 \\
(0.144)\end{array}$ & $\begin{array}{l}34.4 \\
(0.112)\end{array}$ & 0.184 \\
\hline & G5 & $\begin{array}{l}43.8 \\
(0.106)\end{array}$ & $\begin{array}{l}43.4 \\
(0.586)\end{array}$ & $\begin{array}{l}29.9 \\
(0.099)\end{array}$ & $\begin{array}{l}34.1 \\
(0.426)\end{array}$ & $\begin{array}{l}32.4 \\
(0.090)\end{array}$ & 0.261 \\
\hline & E7 & $\begin{array}{l}10.1 \\
(0.058)\end{array}$ & $\begin{array}{l}13.0 \\
(0.067)\end{array}$ & $\begin{array}{l}14.3 \\
(0.070)\end{array}$ & $\begin{array}{l}13.2 \\
(0.061)\end{array}$ & $\begin{array}{l}13.5 \\
(0.061)\end{array}$ & 0.063 \\
\hline
\end{tabular}

$1_{\text {Malfunction of recording system. }}$ 


\begin{tabular}{|c|c|c|c|c|c|c|c|c|c|}
\hline $\begin{array}{l}\text { Time } \\
\text { meEc) }\end{array}$ & $\begin{array}{c}\text { TiF } \\
X \\
(i n)\end{array}$ & $\begin{array}{c}\text { TiF } \\
y \\
\text { (in) }\end{array}$ & $\begin{array}{l}C C_{i} \\
x \\
(i n)\end{array}$ & $\begin{array}{l}\mathrm{CG} \\
y \\
(\mathrm{in})\end{array}$ & $\begin{array}{l}\text { FH } \\
x \\
\text { (in) }\end{array}$ & $\begin{array}{l}\text { EH } \\
y \\
\text { (in) }\end{array}$ & $\begin{array}{c}C G \\
\text { AnS } \\
\text { ( DES }\end{array}$ & $\begin{array}{l}\text { ILAE } \\
\text { CFSC } \\
\text { ( DESS) }\end{array}$ & $\begin{array}{l}\text { IHAS } \\
\text { IHII } \\
\text { (JEE) }\end{array}$ \\
\hline 0.000 & 43 & 67 & 000 & 000 & 11.505 & 1.867 & $4+62$ & & \\
\hline & 284 & & & 001 & .504 & $7 \div 6$ & 0.417 & & \\
\hline$\therefore .410$ & $17+3.34$ & 07 & 0.057 & 955 & \pm 1.611 & 330 & & 9 & 27 \\
\hline 7.615 & 17.207 & 0.813 & 0.114 & 0.050 & 11.771 & 1,393 & 2.745 & $1 \div 734$ & 7 \\
\hline $12+521$ & $17.01 \%$ & 1,561 & 0.283 & 0.159 & 11.675 & 0.978 & 4,855 & 3.221 & \\
\hline & 759 & 2.690 & 0,453 & 0.254 & 12.034 & 0.386 & 8.239 & 5.497 & \\
\hline 31 & $16+367$ & 4.067 & 0.521 & 0.367 & 12.234 & 0.381 & 12.509 & 8.347 & \\
\hline $22+436$ & 15.717 & 5.327 & $0.5+\frac{1}{4}$ & 0.471 & $12: 330$ & 0.971 & 16.355 & 11.026 & \\
\hline $4 i$ & $15+\frac{1}{6} 65$ & 6.592 & 56 & 0.633 & 12.316 & 0 & 20 & 72 & \\
\hline & 14.375 & 5 & 867 & 76 & 12. & & & & \\
\hline 32 & $14 \cdot 274$ & 8.857 & 32 & 0. & 12 & & $27+246$ & 9 & $=$ \\
\hline 50 & 13.656 & 58 & 1.396 & 1. & $12+175$ & 78 & $30+347$ & $5 \overline{5}$ & $3 r$ \\
\hline $38: 462$ & 13.091 & 10.842 & 1.562 & 1.289 & 12.056 & 52 & 33.332 & 23 & \\
\hline 41,567 & 12.477 & 702 & 1.783 & 1.455 & 12.101 & 3.746 & 35.731 & 33 & 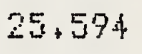 \\
\hline 44.872 & 11.814 & 4.33 & 1.9 .47 & 1.622 & 1 & & $39: 411$ & 82 & \\
\hline 48.077 & 11 & 4 & & & & & & & \\
\hline 51.282 & $10+485$ & 95 & 31 & 56 & 11. & 16 & 45 & 32 & - \\
\hline $54: 437$ & $7+888$ & $14+643$ & $2+495$ & 2 & 11.775 & 4.577 & +11 & 81 & 3 \\
\hline 57.692 & $8+295$ & 347 & 2.650 & $2+410$ & 11.623 & 4 & $47 \div 520$ & 2 & 3 \\
\hline 397 & 3.745 & 1 & & & 1 & & 8 & & \\
\hline & 52 & & & & & & & & \\
\hline 98 & 5 & 17 & & & 9 & 8 & 61 & 8 & \\
\hline 13 & & 17 & & & 11 & & 89 & 52 & \\
\hline 73.718 & 6.527 & 18.102 & 3.483 & 3 & $11+171$ & 4. & 55,524 & 45 & \\
\hline 76.923 & 6.056 & 13.455 & 3.701 & 3.667 & 11.169 & 4.942 & 50.020 & 47.202 & 40. \\
\hline $80+128$ & 5.6 .37 & 18.920 & 3.865 & 3.890 & $11+112$ & $4+94$ & $57: 733$ & 48.687 & 49 \\
\hline & 5.156 & 331 & & 4.072 & 11. & 4.8 & $59 \cdot 201$ & 80 & \\
\hline & 4.754 & 22 & & $4+i$ & 11. & 4.7 & 57 & 5 & 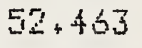 \\
\hline 44 & 4.639 & 34.7 & 4. & 4 & 11. & 4.478 & 57 & 17 & 53 \\
\hline $97+747$ & 4.536 & $20+071$ & $4: 525$ & 4.773 & 11.286 & $4: 302$ & 59,602 & $57+450$ & 53,407 \\
\hline 96.154 & 4.480 & 20.184 & 4.580 & 4.876 & $11.45 \frac{1}{1}$ & 4.067 & 57.594 & 52.723 & 53. \\
\hline & & & & & & & & & \\
\hline & & 20 & & & & 3.578 & $58+346$ & & \\
\hline & $4+702$ & $20+436$ & 4.971 & 5.431 & 11.795 & 3.421 & $57: 4 \frac{4}{8} 7$ & $52+723$ & 53 \\
\hline
\end{tabular}




\begin{tabular}{|c|c|c|c|c|c|c|c|c|c|}
\hline $\begin{array}{c}\text { Time } \\
\text { (msec) }\end{array}$ & $\begin{array}{l}T i p \\
x \\
(i n)\end{array}$ & $\begin{array}{l}\text { TiF } \\
y \\
\text { in }\end{array}$ & $\begin{array}{l}\text { CG } \\
x \\
\text { in) }\end{array}$ & $\begin{array}{c}C G \\
Y \\
(i n)\end{array}$ & $\begin{array}{l}\text { FiH } \\
x \\
(\text { in })\end{array}$ & $\begin{array}{l}\text { FiH } \\
y \\
(i n)\end{array}$ & $\begin{array}{c}\text { CG } \\
\text { Ans } \\
\text { (des) }\end{array}$ & $\begin{array}{l}\text { IASE } \\
\text { CFSE } \\
\text { (UES) }\end{array}$ & $\begin{array}{l}\text { IASE } \\
\text { IHII } \\
\text { (GES) }\end{array}$ \\
\hline 0.000 & 423 & 127 & 000 & 000 & 274 & 1.859 & 0.000 & 5000 & \\
\hline $3.20=$ & .365 & 0.001 & 0.056 & .001 & 11.327 & $1+7+1$ & 0.417 & & \\
\hline 6.410 & 414 & 0.24 .6 & .057 & 055 & $11+435$ & 1.622 & & & \\
\hline & 296 & & & & 33 & 03 & 863 & & \\
\hline $12+821$ & $17 \cdot 224$ & 1.051 & & & & 5 & & & \\
\hline 16.026 & 17.090 & $1+7 \frac{149}{7}$ & & . 156 & $11+757$ & 0.708 & 5.645 & 3.737 & \\
\hline $17 \cdot 231$ & & 2.683 & & .263 & & 0.432 & 8.368 & & \\
\hline & & & 0.730 & & & & & & \\
\hline & 16.076 & 4,798 & 0.897 & 534 & 12.161 & & 4.527 & & \\
\hline 29 & 693 & 5.744 & 1,008 & 641 & 12.207 & & & & \\
\hline & & 6.745 & 17 & & 12.253 & & & & \\
\hline 36 & & 7.566 & & & $12+191$ & & 60 & & \\
\hline 38.462 & $14: 483$ & 8.4 & & & 12.238 & & & & \\
\hline 41.667 & 14.048 & & 06 & & 12.230 & & $27+274$ & & \\
\hline 44.872 & & 7.868 & 1.672 & 1.472 & 12.277 & 2.413 & $29+286$ & & \\
\hline 48.077 & 13.183 & 0.542 & 1.537 & 641 & 12.273 & 2.650 & 31.074 & 23 & 2 \\
\hline 82 & & 213 & 12 & 09 & $12+375$ & 12 & & & \\
\hline 54,457 & $12+326$ & 4 & 22 & 77 & 16 & & & & \\
\hline 57.592 & $11+900$ & 473 & 2.388 & 146 & 12.423 & 92 & 45 & 25. & \\
\hline 60.877 & \pm 1.430 & 770 & 2.553 & 74 & 12.566 & & $37+531$ & & \\
\hline 64 & 11.067 & 550 & 2.719 & $2.602^{\circ}$ & 12.418 & 54 & 33.701 & 4 & 7 \\
\hline & 344 & & & & 4 & & & & \\
\hline & 197 & & & & & & & & \\
\hline & 9.932 & & 5 & & & & & & \\
\hline 76 & 7.637 & & & & 12. & & & & \\
\hline & 7.395 & 891 & 3.382 & 3.631 & $12+464$ & .703 & & & \\
\hline $83+333$ & 9.053 & & 3 & 62 & $12+463$ & & $44+7$ & & \\
\hline 86.537 & 8.918 & 80 & 3.767 & 38 & 12.572 & 29 & 36 & & \\
\hline 44 & 8.571 & $T$ & & & 28 & & & & \\
\hline & 5 & 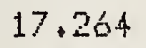 & & & & & & & \\
\hline 96 & 7 & 46 & & & 3 & 9 & 33 & & \\
\hline & 7.887 & 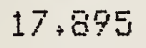 & 4 & & 12.903 & 85 & & & \\
\hline $02+564$ & 7.716 & 178 & & 12 & 12.7 & 77 & 86 & 4 & \\
\hline & 473 & & & & $1:$ & & & & \\
\hline & 75 & & & & & & & & \\
\hline & 5 & & 4 & & & & & & \\
\hline & & & & & & & & & \\
\hline & & & & & & 7 & & & \\
\hline & & & & & 13.3 & & 47.525 & 45 & 47. \\
\hline & 6.936 & 0 & 5.2 & & $13+5$ & 0.796 & 47.3 & 48 & 43. \\
\hline & 6.773 & & 5.7 & & & & 25 & & 48 \\
\hline & 777 & & -1 & 16 & & & & & \\
\hline & 75 & & & & & & & & 83 \\
\hline & 6.722 & & & & & & & & 01 \\
\hline & 67 & & & & & & 77 & 50 & 49.916 \\
\hline & 6.671 & & & & 13 & & 46.523 & 50 & 50. \\
\hline 4.436 & 6.559 & 20.9 & & & 14. & & & & \\
\hline & & & & & 1 & & & & \\
\hline & & & & & & & & & 50 \\
\hline & & & & & & & & & 350 \\
\hline & 6.617 & & & & 14.189 & 1.082 & 45.915 & 51 & 51.103 \\
\hline & 6.618 & 21.567 & & 8.904 & 14.244 & 1.200 & 45.873 & 51.724 & 51,25 \\
\hline 166,667 & 6.620 & $21+676$ & 5.899 & 9.021 & $14+40 \overline{8}$ & 1.435 & $45+753$ & 51.380 & 51.39 \\
\hline
\end{tabular}


10 FiEH

20 FED

30 FEE

40 FEM

50 FEH

SD FEE

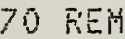

B0 FEEH

90 CALL 3

$100113 \mathrm{X} \pm 117,17), 11(17,17)$

110 IIIA X3! 300$), Y 3(300), x, 3(300), Y 4(300), X 5(300), Y 5(300)$

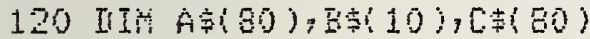

130 IIIU IIt(20), L $(20),($ क $(10)$

140 III Fis $(4), 5+4), T+3)$

150 IIH U⿻ 120 )

160 IIIM IV $(20)$

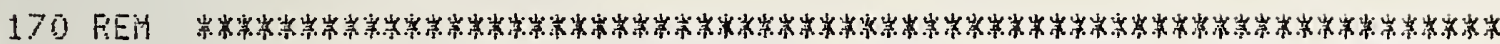

180 REH

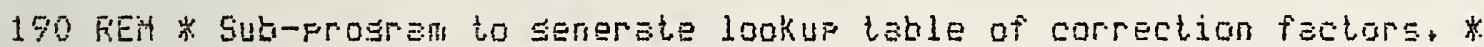

200 FEEM

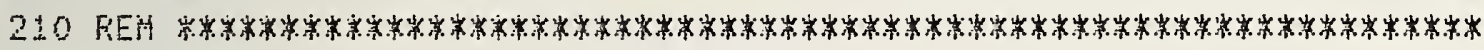

220 FFIIHT "

230 PFIIHT "Q7\%"

240 PFIHT "Hsit ! ! ! The computer is now seneralins a lookup"

250 Finst "table of correction factors."

260 FFINT " $7 \% "$

270 PFIUT " "

$230 \mathrm{FuF} I=1$ TO 17

$290 \mathrm{FuF},]=1$ TO 17

300 FEEÁI $X 1(I, 3)$

310 REXT I

320 MEXT I

330 FOR $K=1$ TO 17

340 FOR $L=1$ TO 17

350 FEAII Y $1(K, L)$

360 HEXT L

370 PUEXT K

330 मिE

390 FiEH

400 PRIAT " "

410 PFIAST "

420 FRINT "Q7\%"

430 PRIAT "TyFe the name of the data file to be read:"

140 LISFUT Q\$

450 IF [1\$=" THE EA EOTO 3150

460 FRINT "11\%

470 PRINT "

480 FFIIIT "

490 FEIHT " "

500 Frint "Tupe tre tirst, line number to be andelsed"

510 IHFUT $Z 1$

520 FFIAT " 411 \%

530 FRIAT "

540 PRIBT "

550 FEIST "n

560 PRIMT "Tupe the last line number to be enelyzed""

570 IAPUT 22

$5 E O$ PFIMT " $11 \%$

590 FRIHT "

600 PFINT "

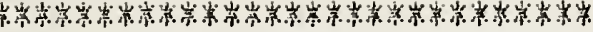

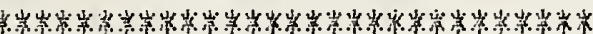

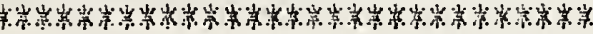

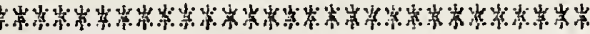



410 F"̈IMT "I

620 IF $72=Z 1$ THEU GOTO 3150

630 IF 2231 THEN QUTO 3150

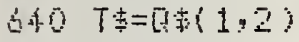

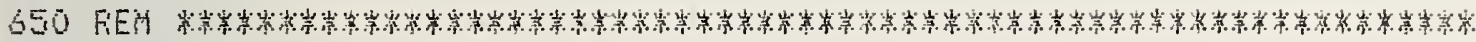

660 FEE

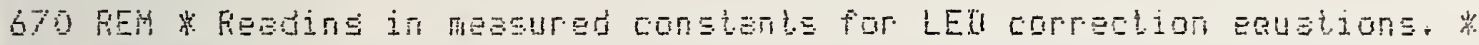

690 RE

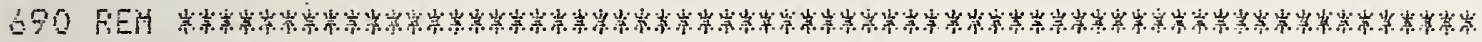

700 FEAI A1,A2,C1, [2, :1, F:2,L3,L4,A3,4A

710 IF T\$="G1" THEN $60 T 0$ G30

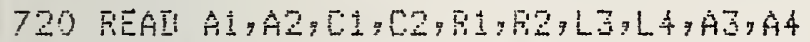

730 IF TS="G2" THEY COTO 630

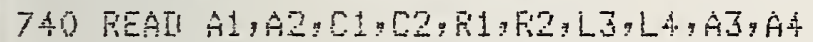

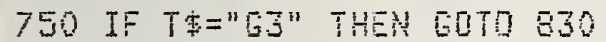

760 REAI A1, A2, CA, C2, $11,52, L 3, L 4, A 3, A 4$

770 IF T\$="G4" THEN GOTO 830

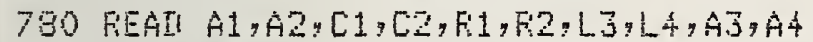

790 IF T\%"G5" THE GQTO 830

800 REAII AI, A2, $\left[1, C_{2}, F_{1}, F 2, L 3,14, A 3, A 4\right.$

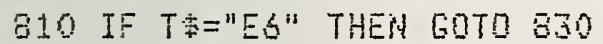

Q20 FEALI A1, A2, C1,C2, HI, R2,LJ,LA,A3,A4

830 L克="AC "+口宗十",7F!"

G木O CALL 4 ,L束

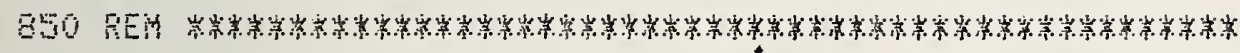

360 FE⿰亻弋 京

索

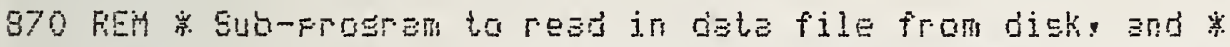

880 REE w to correct for addition of "12g" t. ABCII velue *

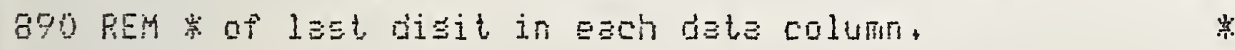

900 FiE

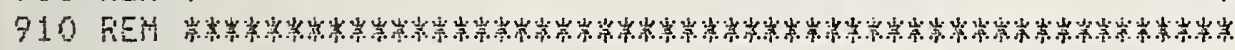

920 FFIITT "

930 FPIAT "४7\%"

740 FRIAT "heit ! ! ! The computer is now resdins in tha dete"

750 FEIMT "file fron the flopfy disk."

960 FEINT "\#

970 FFINT "

$780 \mathrm{FOF} I=1$ TO $Z 2$

790 LINFUT DN $(7)$ IA

1000 FOF $\quad$ U $=6$ TO 11

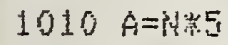

$1020 \quad B+=A+(A, A)$

1030 CALL $37, E \$, 11$

$1040 \quad \forall=y-128$

1050 CALL 3., V, E⿰

$1060 \quad B=A-4$

$1070 \mathrm{C}=\mathrm{A}-1$

$1080 \quad U 5=A+(E, C)+B D$

$1090 \mathrm{I}(\mathrm{A})=\mathrm{VAL}\left(\mathrm{V}^{5}\right)$

1100 HEXT H!

$1110 \quad Y 3(1)=\operatorname{II}($ \&)

$1120 \mathrm{Y3}(\mathrm{I})= \pm(7)$

$1130 X(I)=I($ I)

1140 Y4(I) $=I(19$ )

$1150 \times 5$ ( I $)=[(10)$

1160 Y5ㄴ(I)=[(11)

1170 MEXT I

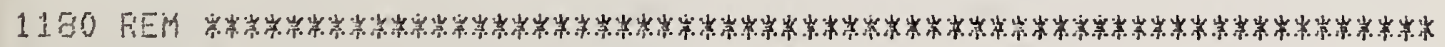

1170 FEEY *

1200 FEth * Sub-frosrant to carrect for selseot lens distortions, and 


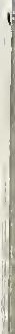




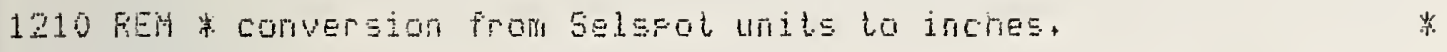

1220 FED

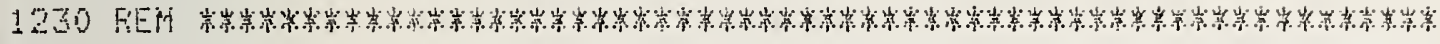

12 SO FEINT "

1250 FRINT "४\%"

$1260 \mathrm{Frit}$ "best ! ! ! The confuter is now correcting for selegot"

1270 FRTH "IEnE distortions, snd convertins from selspot units to"

1280 FRTHT "inches:"

$12 \% 0$ FFINT "n

1300 FRTAT "O?"

1310 FOF $H=Z 1$ TO 22

$1320 \mathrm{FOF} Z \mathrm{Z}=1 \mathrm{TO}$

1330 IF $z=1$ THEN $x=1023-\gamma 3(u)$

1340 IF $Z=1$ THEM $Y=Y 3(\omega)$

1350 IF $Z=2$ THES $X=1023-x+4(H)$

1360 IF $Z=2$ THEN $Y=Y+W$ (W)

1370 IF $z=3$ THEN $X=1023-x 5(4)$

1380 IF $Z=3$ THEN $Y=Y 5(U)$

$1370 \quad H=I N T(X / 64)+1$

1400 i $=I M T(Y / 64)+1$

$1410 \mathrm{~F}=(\mathrm{X} / 64)-\mathrm{H}+1$

$1420(Y=(Y / 64)-1+1$

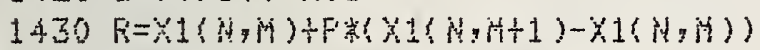

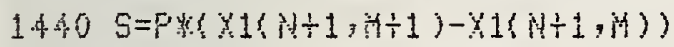

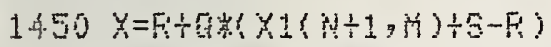

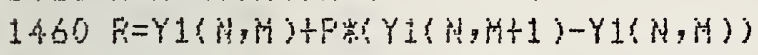

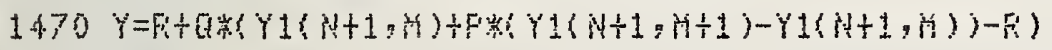

1480 FEEH

1450 FEH "C" is the conversion factor from tenths of uillineters

1500 REti to inches:

$1510[=1 /(10$ ) 25 년 4 )

1520 PED

1530 FEr "Il" is the fectar for adjustins the distence from the

15 fre Fe camere to the srid, from the initiel calibration

1550 FEy distance, of 125 inches, to the ectual test condition.

1560 FEH

$1570 \quad I=125 / 154$

1500 IF $X<0$ THEN $X=0$

1590 IF $Y<0$ THEM $Y=0$

$1600 x=[\% I I X X$

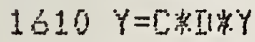

1620 IF $Z=1$ THEN $X 3:(U)=A E S(X-53)$

1630 IF $Z=1$ THEN $Y 3:(U)=Y$

1640 IF $Z=2$ THEN $X 4(U)=A B S(X-53)$

1650 IF $Z=Z$ THEN $Y 4(\mathrm{H})=Y$

1660 IF $Z=3$ THEN $Y$ S $(H)=A B S(X-53)$

1670 IF $Z=3$ THEN $Y S(H)=Y$

1690 PEXT $Z$

1690 施ET W

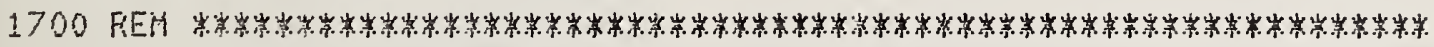

1710 SEA *

1720 FEM * Sut-frosran to frint out corrected and scaled deta file.

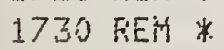

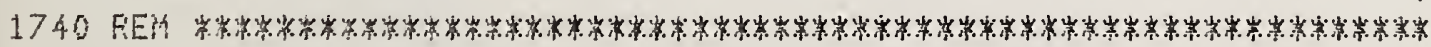

1750 FEIHT "

1760 F

1770 Fritt "Wat ! ! ! The computer will naw frint dut the corrected" 1730 FrTUT "and scaled date file."

1790 PFINT "

1000 FFINT "C.7" 

1310 FEd At the tine chosen as ton, the following constants ere set?

$1820 \quad 10=Y 3(Z 1)$

$1830 \quad H 0=x(3171)$

$1340 \quad Y 0=Y 4(Z 1)$

$1850 \times 0=\times 4(Z 1)$

$1960 \quad 51=x 5(Z 1)+51$

$1870 \quad 52=Y 5(Z 1)+F 2$

$1390 \quad Q 1=K A(Z 1) \div[1$

$1890 \quad[2=Y 4(Z 1)+C 2$

1900 FriMT DN $(2)^{\prime \prime}$

$"+0$ 业

1910 FRTRT OH $(2)^{11}$

1720 FFINT OS (2)"

$1930 \quad[\%="$

$1740 \quad 5+="[6$

TiF TiF

C.6

CE FH

Fin "

$1950 \quad \mathrm{C}=\mathrm{C}=+\mathrm{F}+\mathrm{5}$

1960 FFINT UA (2) I粦

1970 C $\$="$ Time $X$

1980 I!t="fins CFSE IUII"

1970 C $5=0 .+5+5$

2000 FRIMT an (2)C

2010 C蛪="

2020 I年=" "

2030 (ot=" (m5ec) (in) (in) (in) (in) (in) (in) (d"

$2040 \mathrm{It}="$ es) (des) (des)"

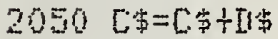

2060 FFITT GIA $(2)$ C

2070 FFIHT OAS $(2)$ "

2000 Fen Computstion snd conversion of LET fositions to

2090 REA desired lacstions.

2100 FOF $\quad U=Z 1$ TO $Z 2$

$2110 \mathrm{AB}=\mathrm{AT}(\mathrm{W}(Y 3(\mathrm{U})-Y 4(U)) /(X 3(\mathrm{U})-\mathrm{X}+(\mathrm{U})))$

$2120 \quad A 7=A T H((10-Y 0) /(H O-X 0))$

$2130 \quad A=A B-A 9$

$2140 T 1=X 3(U)+A 14 C 0 S(A)-A 2$ USIMU)

2150 T2=Y3(U)十A1

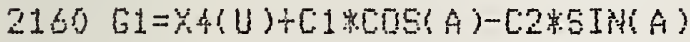

$2170 \quad(2=Y 4(U)+C 1+5 I$ (N) $A)+[2 * \cos (A)$

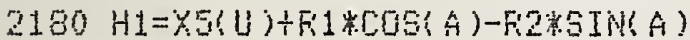

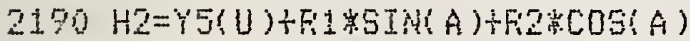

2200 II $=\dot{A} T$ H $((T 2-52) /(T 1-51))$

$2210 \mathrm{II}=\hat{A T H}(\mathrm{UO}+\mathrm{A} 2-52) /(40+A 1-51))$

2220 IIIIIE-II?

2230 $T 1=T 1-41$

$2240 \quad T 2=T 2-42$

$2250 \quad 61=61-01$

$2260 \quad 62=62-022$

$2270 \mathrm{HI}=\mathrm{H1}-\mathrm{G1}$

$2280 \mathrm{H2}=\mathrm{H2}-\mathrm{C2}$

2290 T3=T1+A3*COS(A)-A4*SIH! A)

2300 TA=T2+A.3*SIN(A)+A4*COS(A)

$2310 \quad E=A T T H(T 4-L 4) /(T 3-L 3))$

2320 $A=f(x, 180 / 3.14159$ )

2330 IIII $(180 / 3.14159)$

$2340 \quad \overline{1}=1.4(180 / 3.14159)$

$2350 T=(L-Z 1)(\omega, 1000 / 312)$

2360 FEIMT USTHG "MGE, EQE", T, T1, T2, G1, G2,H1, H2, A, II, H

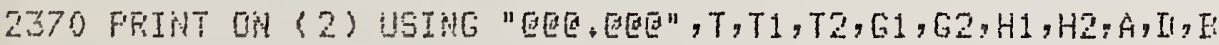

2380 HEXT U

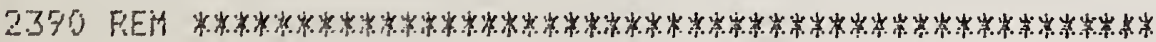

2 S. 00 FEH \% 



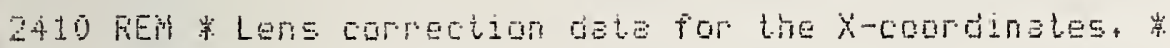
$2420 \mathrm{FE}$ 政

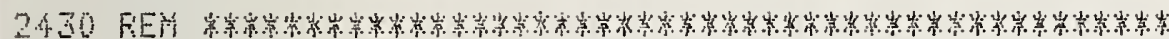

2440 IIATA $-674,437,15459,2647,374,44835,5914,7000,0097,9185410273,11343$

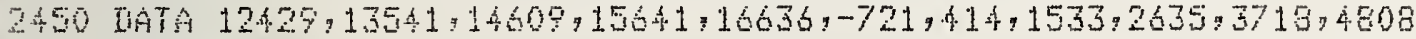

2460 IIATA 5999

2470 IATA $3990,0081,9164,10249,11339,12422,13499,14579,15660,16743,-749$

2480 IATA $395,1517,2618,3672,4703,5082,6777,8070,7147,10232,11332,12415$

2470 IATA 13474,14562, 15672, 16805, -758, 379:1477,2574, 3666,4753,5863,6960

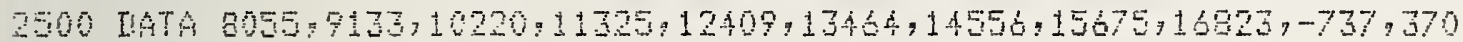

2510 IATA $1470,250193640,473595041,6937,8033,9125910210,11315,12403$

2520 IIATA 13 年 70

2530 IATA $14568,15668,16777,-736,35591445,2533,3614,4710,5810,6918,8014$

25 A DATA $7111,1020 \%, 11311,12402,13480,14568,15663,16734,-752,334,1421$

2550 IIATA $2506,3568,469375789,6872,7974,9092,10195,11311,12405 \eta 13474$

2500 IATA $14561,15659,16758,-7639320,1405,2487,3573,4669,5775,6080,7984$

2570 I!TA $9083,10186,11304,12399,13467,14554,15053,16764,-772,311,1396$

2980 IATA $2481,3565+46629571,6977,7932,7077,10180,11293,12397,13456$

2570 IATA 14545, 15646.16757,-767,300,1369,2474,3557,4655,5769,6873,7972

2600 IATA $7067: 10167,11260,12374,13444,14531,15630,16737,-796,294,1303$

2610 IATA $2470,3552,4650,5765,3867,7964,9057,10154,11263,12356,13420$

2620 IATA $14517,15617,16730,-780,296,1381,2466,3549,4646,5756,6859,7957$

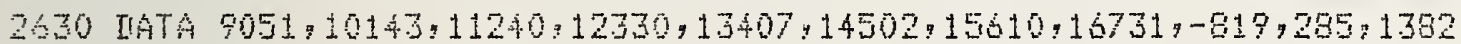

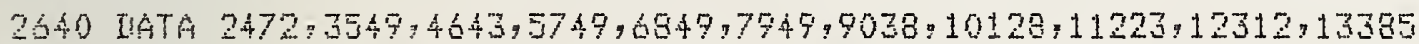

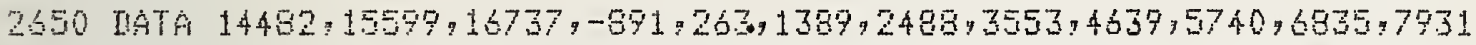

2660 WATA $7015,10105,11211,12299,13355,14453,15568,16732,-893,256,1381$

2670 IIATA $2452,3552,4640,5737,683397929,7011,10077,11179,12285,13353$

2680 IIATA $14447,15566,16713,-3527259,1364,2462,3550,4645,574396841,7938$

2690 DATA 9020 , 10103,11159,12277, 13372,14457,15536,16610,-770,271, 1339

2700 IIATA $2427,3547,4652,5753,6556,7957,9040,10118,11160,12265,13412$

2710 IIATA $14484,15499,16453$

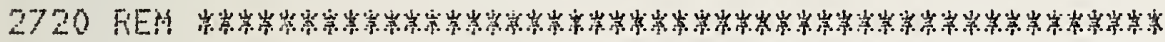

2730 FES

27fo REA w Lens correction data for the Y-coordinates.

2750 FEM

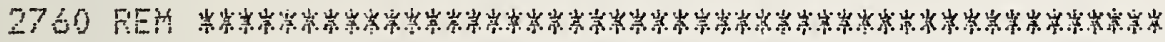

2770 IIATA $-1035,-1137,-1150,-1192,-1137,-1115,-1103,-1091,-1071,-1041$

2780 IATA $-1013,-981,-770,-992,-976,-933,-859,56,-9,-44,-48,-17,-2,5,23$

2790 IIATA $48,69,58,1059119,129,137,146,155,1163,1122,1097,1091,1108$

2000 IIATA $1116,1126,114591171,1186,1199,1206,1219,1246,1251,1240,1211$

2810 IATA $2300,2261,2233,2230,2240,2243,2256,2273,2296,2309,2319,2320$

2520 IATA 2332 , 2361, 2364,2347,2309,3460,3406,3372,3361,3375,3384, 3395

2930 IIATA $3407,3421,3437,3448,3451,3456,3467,3471,3471,3467,4611,4555$

2540 IATA $4522,4510,4524,4533,4543,4552,4560,4575,4585,4557,4571,4596$

2850 1ATA 4601,4607,4614,5756,5714,5698,5675,5688,5695,5702,5708,5715

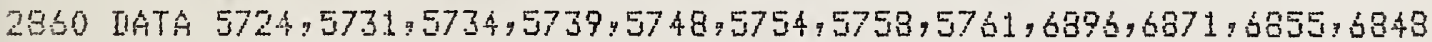

2570 IIATA $6854,6857,6861,656496868.6873,6876,6877,6382,6891,6898,6703$

2880 IIATA $6907,8033,8029,8027,8025,8024,8023,8021,8022,8023,3023,8023$

2890 IIATA $8020,8023,8033,8041,8048,8054,9181,9197,9209,9211.9204,9202$

2900 IATA $7202,9202,9200,9196,9189,9173,9172,9189,7200,7203,7212,10313$

2910 IIATA $10351,10373,10380,10367,10351,10359,10354,10348,10343,10334$

2920 IIATA $10313,10311,10330,10342,10351,10357,1 \pm 421,11434,11522,11535$

2930 IIATA $11515,11503,11471,11477,11462,11458,11453,11443,11443,11456$

2940 IATA 11467,11477,11486,12541,12611,12652,12665912542,12620,12614

2950 IATA $12597,12579,12577,12572,12557,12557,12565,12576,12593,12616$

2960 IATA $13673,13731,13763,13772,13751,13738,13727,13714,13699,13699$

2970 IATA $13691,13667,13655,13651,13666,13701,13757,14739,14822,14867$

2780 IIATA $14878,14945,14830,14822,14809,14793,14772,14783,14753,14741$

2990 IATA $14744,14756,14778,14812,15759,15890,15962,15978,15924,15904$ 

3000 IATA $15902,15989,15869,15866,15955,15023,15815,15838,15842,15833$

3010 IATA $15807,16736,16937,17047,17072,16970,16763,16967,16951,15927$

3020 IATA $16921,16709,16877,16976,16731,16924,16867,16753$

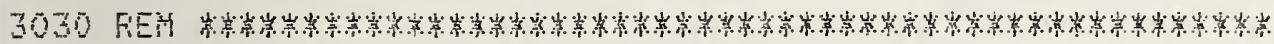

3040 FiEH 岸

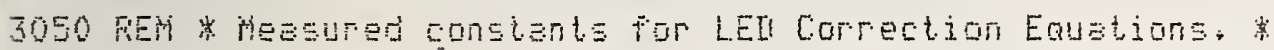
3060 FEE

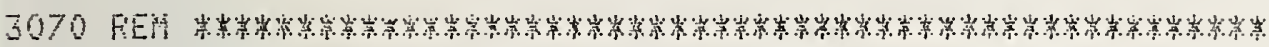

3080 IIATA $-1,-4+4,0,0,-2,12,+69,6,06: 2,44,-1,12,-, 93$

3090 IATA $-1,31,1,06 \%, 4 E-1,0,-1,56,-1,31,4,06,3,-1,06,-, 93$

3100 IATA $-1,31,480,-.33, .85,-2,42,5,5,75,2,31:-, 97,-, 74$

3110 IATA $-75,1+12,0,-75,-2,56,1662,7,1,25,-1,13,-1,12$

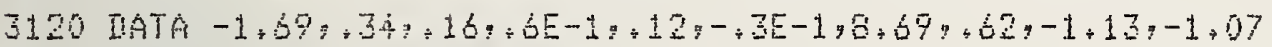

3130 IATA $-1,25,0,02,0,5,-2,4 \frac{4}{4},-12,0,0,0,0$

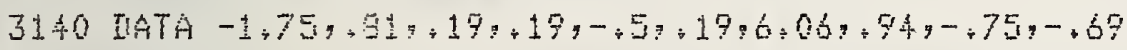

3150 CALL 3

3160 ENII 

NBS-114A (REV. 2.80)

U.S. DEPT. OF COMM.

BIBLIOGRAPHIC DATA

SHEET (See in structions)

1. PUBLICATION OR
REPORT NO.
NBSIR $82-2559$

2. Performing Organ. Report No. 3. Publication Date

August 1982

4. TITLE AND SUBTITLE

Evaluation of Chain Saw Kickback Motion using an Optoelectronic Measurement System

5. AUTHOR(S)

Donald Robinson and Charles Federman

6. PERFORMING ORGANIZATION (If joint or other than NBS, see instructions)

NATIONAL BUREAU OF STANDARDS

DEPARTMENT OF COMMERCE

WASHINGTON, D.C. 20234

9. SPONSORING ORGANIZATION NAME AND COMPLETE ADDRESS (Street. City. State, ZIP)

7. Contract Grant No.

8. Type of Report \& Period Covered

10. SUPPLEMENTARY NOTES

Document describes a computer program; SF-185, FIPS Software Summary, is attached.

11. ABSTRACT (A 200-word or less factual summary of most significant information. If document includes a significant bibliography or literature survey. mention it here)

In 1980 the Consumer Product Safety Commission initiated the in-house development of a mandatory standard to address chain saw kickback. Part of that effort involved relating known chain saw energy levels generated during kickback to the final angle that a saw might travel when held in the hands of a chain saw operator. The present report describes the experimental program developed at NBS to determine the relationship between kickback energy and chain saw motion during hand-held kickbacks for selected samples of consumer-type chain saws and volunteer test subjects. The measurement system employed in this research included a computer-controlled optoelectronic system for measuring the displacements of selected points on the test saws and test fixture during simulated kickbacks. Included in the report is a description of the test equipment and procedures, the experimental design, and analyses of the measured displacement data for chain saws having known values of kickback energy.

12. KEY WORDS (Six to twelve entries; alphabetical order; capitalize only proper names; and separate key words by semicolons)

chain saw kickback motion; displacement measurements; kickback energy; optoelectronic measurement system; simulated kickback motion; volunteer test subjects.

13. AVAILABILITY

$\mathrm{X}$ Unlimited

For Official Distribution. Do Not Release to NTIS

Order From Superintendent of Documents, U.S. Government Printing Office, Washington, D.C. 20402.

14. NO. OF

PRINTED PAGES

63

X] Order From National Technical Information Service (NTIS), Springfield, VA. 2216I 

